\title{
Atenuação da luz em meios materiais: uma atividade de modelagem envolvendo três experimentos didáticos
} Attenuation of light by material media: a modeling activity involving three didactic experiments

\author{
Rodrigo Weber*10, Leonardo Albuquerque Heidemann"10, Eliane Angela Veit ${ }^{10}$ \\ ${ }^{1}$ Universidade Federal do Rio Grande do Sul, Instituto de Física, Porto Alegre, RS, Brasil
}

Recebido em 27 de maio de 2020. Revisado em 26 de agosto de 2020. Aceito em 22 de setembro de 2020.

\begin{abstract}
O fenômeno da atenuação da luz pelos meios materiais é pouco discutido nos cursos de Física em nível de graduação, principalmente no contexto das aulas experimentais. Neste artigo, discute-se uma atividade de laboratório sobre essa temática desenvolvida com a metodologia de ensino Episódios de Modelagem. A atividade envolve três experimentos explorados sob a perspectiva da Modelagem Didático-Científica, com o objetivo de dar sentido especialmente ao conceito de expansão de um modelo teórico. A problematização das investigações é derivada de discussões sobre como a poluição da água influencia na zona fótica dos oceanos. Para responder às questões levantadas, é necessária uma expansão do modelo de propagação da luz no vácuo, incluindo processos de absorção e espalhamento da luz pela matéria, que foi desenvolvida com base na Lei de Beer-Lambert. Com as práticas propostas, busca-se destacar como um modelo teórico da Física pode ser aprimorado através da inclusão de efeitos anteriormente desconsiderados, ampliando assim seu domínio de validade e capacidade preditiva, possibilitando a condução de discussões sobre a natureza do processo de modelagem científica em aulas experimentais. Para contrastar empiricamente o modelo teórico expandido, foram realizados três experimentos, cada um deles em um diferente meio material (vidro, solução de água + sal de cozinha e fumaça), com o uso de laser ou lâmpada de filamento. Foi dado particular destaque ao papel das idealizações assumidas no processo de construção, uso e validação do modelo construído, buscando, em cada situação, avaliar as consequências dessas simplificações da realidade. Dos resultados experimentais, conclui-se que: i. o modelo teórico expandido descreve a atenuação da intensidade luminosa em meios materiais com boa precisão e ii. a poluição dos oceanos pode contribuir para aumentar a extinção da luz solar, diminuindo assim sua penetração na zona fótica, reduzindo a taxa de fotossíntese das algas. O presente artigo pode contribuir para a área de ensino de Física não apenas trazendo uma atividade didática de laboratório inovadora, mas também servindo de referência para aqueles professores interessados na aplicação prática de atividades de modelagem, em particular aquelas centradas na expansão de um modelo teórico.
\end{abstract}

Palavras-chave: Lei de Beer-Lambert, atenuação da luz, modelo científico, Episódio de Modelagem.

The attenuation of light by material medium is little discussed in Physics degree courses, especially in experimental classes. In this article, a laboratory activity on this theme is discussed to be conducted with the teaching methodology of Modeling Episodes. The activity comprises three experiments, explored from the perspective of Didactic-Scientific Modeling in order to make sense specially of the concept of expanding a theoretical model. The problematization of the investigations is derived from discussions about how water pollution influences the photic zone of the oceans. In order to answer the questions raised, it is necessary to expand the model of propagation of light in a vacuum, including processes of absorption and scattering of light by matter, which was done through Beer-Lambert's law. With the proposed practices, it is sought to highlight how a theoretical model of Physics can be improved through the inclusion of previously disregarded effects, thus expanding its domain of validity and predictive capacity, enabling the conduct of discussions on the nature of the scientific modeling process in experimental classes. In order to empirically contrast the expanded theoretical model, three experiments were done, each one of them in defferent media (glass, solution of water + table salt and smoke), using lasers and lamps as light emitting source. Particular emphasis was given to the role of the idealizations assumed in the process of construction, use and validation of the constructed model, seeking to evaluate, in each situation, the consequences of these simplifications of reality. From the results of the experiments, it is concluded that: i. the expanded theoretical model describes the attenuation of light intensity in material media with good precision, and ii. the pollution of the oceans can contribute to increase the extinction of sunlight, thus decreasing its penetration in

\footnotetext{
* Endereço de correspondência: rodrigoweberpereira@gmail.com
} 
the photic zone, reducing the photosynthesis rate of the algae. This article can contribute to the field of Physics teaching, not only bringing an innovative laboratory teaching activity, but also serving as a reference for those teachers interested in the practical application of modeling activities, in particular those focused on the expansion of a theoretical model.

Keywords: Beer-Lambert Law, attenuation of light, scientific model, Modeling Episodes.

\section{Introdução}

A aprendizagem nas aulas de laboratório de Física tem sido alvo de atenção há longa data ${ }^{1}$ [1, 2]. Nessas aulas os estudantes têm dificuldades para mobilizar os conhecimentos teóricos nas atividades práticas e, com muita frequência, não se motivam tanto quanto seria esperado, especialmente em cursos de Física 3, 4.

Uma alternativa para diminuir a distância entre teoria e prática em aulas experimentais é focar no processo de modelagem científica [5-12]. Nessa perspectiva, o professor tem oportunidade de abordar os conhecimentos científicos relevantes para a situação investigada, e também de incitar debates sobre epistemologia e natureza da ciência. Debater, por exemplo, sobre o caráter representacional de modelos teóricos da Física e o papel das simplificações da realidade no processo de construção de modelos científicos [13-16] é uma forma de contribuir para que os estudantes superem, ainda que parcialmente, a ideia ingênua de que modelos científicos são representações exatas e fiéis dos fenômenos que se propõem a descrever [17].

Para motivar os estudantes, uma possibilidade é levá-los a vivenciar nos laboratórios didáticos situações experimentais mais abertas do que as costumeiramente propostas, dando oportunidade para que tenham tomada de decisão nas suas investigações, favorecendo o desenvolvimento de suas autonomias. Esse tipo de abordagem favorece maior interação entre os integrantes dos grupos, pois as decisões devem ser coletivas, dialogadas com o professor, promovendo um ambiente mais propício para a aprendizagem [1].

Uma metodologia de ensino que contempla, simultaneamente, essas duas alternativas (enfoque no processo de modelagem científica e autonomia no laboratório) é denominada Episódio de Modelagem (EM) [18]. O ponto fundamental de um EM é propor uma situação-problema do mundo real, de preferência um problema contemporâneo, com potencial para despertar o interesse dos estudantes. A situação-problema do EM abordado neste artigo é a seguinte ${ }^{2}$,

A fotossíntese, realizada pelas algas marinhas na chamada Zona Fótica do oceano, é um processo fundamental para a vida na Terra, afinal esses organismos

\footnotetext{
1 Pode-e considerar que a pesquisa em Ensino de Física teve sua origem na década de 1950, com o desenvolvimento dos grandes projetos, como o famoso PSSC, cujo foco eram as aulas experimentais 1 .

2 Este Episódio de Modelagem foi desenvolvido na disciplina de Física Experimental IV com licenciandos e bacharelandos dos cursos de Física da UFRGS no segundo semestre de 2019.
}

produzem mais oxigênio que as árvores! Por isso, é imprescindivel que a luz proveniente do Sol consiga atravessar a atmosfera e chegue a uma determinada profundidade do oceano. Nesse contexto, é essencial entender a dinâmica por trás da atenuação da luz ao atravessar os diferentes meios materiais, já que a poluição, tanto do ar quanto do oceano, tem potencial de influenciar a produção de oxigênio na Terra.

Como se dá a atenuação da energia luminosa ao atravessar meios materiais? Como a poluição dos oceanos pode influenciar a fotossintese das algas por meio de alterações na atenuação da luz solar?

Essa situação-problema difere das tradicionais, pois envolve uma questão ampla, que tem sentido além do contexto acadêmico, e que será desdobrada em questões mais específicas, a serem respondidas por meio de investigações no laboratório didático. Por exemplo, qual o comportamento da energia luminosa de um laser quando atravessa uma solução de água e sal de cozinha, com concentração de $\mathrm{NaCl}$ semelhante à observada na água do mar?

Em atividades mais fechadas, esse tipo de questão seria apresentada diretamente ao estudante, possivelmente com um roteiro já indicando a montagem experimental e os procedimentos para a coleta e análise de dados. Sem grande interesse na questão em si, a atividade se resumiria a todos os grupos realizando um mesmo experimento e elaborando relatórios com resultados já bem conhecidos.

Muitos estudantes e professores gostariam de revolucionar as aulas de laboratório pela introdução de experimentos de impacto com equipamentos sofisticados. A nossa pretensão é encantar o estudante pela física envolvida; pela possibilidade de mobilizarem conhecimentos de física para responderem questões tão relevantes como, por ex., quão nocivos são os efeitos da atenuação da luz para a produção de oxigênio na atmosfera? Deseja-se levá-los a compreender que as investigações em laboratórios (didáticos ou não) se valem de experimentos criados deliberadamente para serem conduzidos e interpretados dentro de um corpo de ideias. Por exemplo, com base em conhecimentos sobre o meio oceânico, busca-se, em uma das investigações propostas no EM, simular o ambiente marítimo por meio de uma solução de água e sal de cozinha. Sabese que os oceanos possuem outros componentes além de água e $\mathrm{NaCl}$, que o sal de cozinha possui impurezas, e que a concentração de $\mathrm{NaCl}$ varia dependendo da região do oceano. No entanto, mais do que encontrar dados precisos sobre a atenuação da luz em uma porção 
específica de água do mar, o objetivo dos EM é proporcionar a construção de conhecimentos em situações contextualizadas e problematizadas, dando sentido aos experimentos simplificados e controlados conduzidos em laboratórios didáticos. A influência das ideias prévias no delineamento experimental também é evidenciada nos experimentos propostos neste EM quando, por exemplo, são utilizados canos escuros ao confinar os meios investigados (líquido ou gás) para que a luz espalhada seja absorvida, haja vista que o modelo científico que dirige a investigação incorpora a idealização de que a radiação espalhada pelo meio não retorna à direção de propagação inicial. Oportuniza-se, com procedimentos como esse, a compreensão de que o controle de variáveis é prática recorrente em laboratório, e que esse controle depende das considerações assumidas no corpo teórico que sustenta a investigação.

Os EM também se diferenciam em vários outros aspectos. Por ex., um episódio se estende, tipicamente, por três ou quatro encontros (com duas aulas conjugadas em cada um), e é composto por quatro etapas (tarefa prévia, discussão inicial, investigações, discussão final), detalhadas na seção 2.2.3 Aqui destacamos informações que acompanham a apresentação da situação-problema desse EM para os estudantes.

A poluição dos oceanos afeta a fotossíntese das algas por outros fatores além da diminuição da intensidade da luz solar. Alguns agentes poluentes podem influenciar a produção de oxigênio tanto pela eliminação de algas, quanto pela mudança radical nos mecanismos bioquímicos desses organismos, que podem passar a produzir menos oxigênio [19. O estudo da fotossíntese de algas é um problema interdisciplinar, que neste artigo é enfocado somente sob o ponto de vista físico da atenuação da luz. Sob esse ponto de vista, a poluição é danosa quando o meio possui partículas de soluto em suspensão, tipicamente microplásticos, esgoto, dejetos químicos, etc. [20, que essencialmente impõem uma barreira mecânica à passagem da luz, dificultando a fotossíntese.

A composição da água do mar é complexa, contendo além de sais inorgânicos, como $\mathrm{NaCl}, \mathrm{MgCl}_{2}$, $\mathrm{KCl}, \mathrm{NaHCO}_{3}$ e $\mathrm{MgSO}_{4}$ em diferentes proporções [21], matéria orgânica. Entretanto, pouco mais de $80 \%$ da concentração iônica no oceano é de $\mathrm{NaCl}$, sendo esse composto e as algas marinhas os principais agentes responsáveis por atenuar a luz no oceano [22, 23]. Assim, uma solução de água e sal de cozinha comum pode servir como uma primeira aproximação para investigar a atenuação da luz nesse ambiente.

Uma questão suscitada por essa situação-problema é: Como poderíamos expandir o modelo teórico de propagação da luz no vácuo de modo a incorporar elementos vinculados com a absorção e o espalhamento da luz na água do mar? Como a construção de resposta a essa questão extrapola os limites de uma disciplina de laboratório, elaborou-se um texto sobre a expansão do modelo de propagação da luz no vácuo, incorporando efeitos de absorção e espalhamento da luz que atravessa meios sólidos, líquidos ou gasosos (pautada na Lei de Beer-Lambert) [24] (subseção 2.2].

Sob o ponto de vista da modelagem, o objetivo desse episódio é destacar como o processo de modelagem centrado na expansão de um modelo teórico de referência pode ser usado para explorar didaticamente o papel das idealizações no processo de construção, uso e validação de modelos científicos, de forma a evocar a mobilização de conhecimentos essenciais para a experimentação em Física.

$\mathrm{Na}$ sequência, passamos a apresentar o embasamento teórico que sustenta as investigações experimentais (seção 2.1 e 2.2, bem como as etapas do Episódio de Modelagem envolvendo atenuação da luz (seção 2.3), os resultados dos três experimentos que compõem esse episódio (seção 3), respostas às duas questões de pesquisas enunciadas (seção 4 ) e, finalmente, os comentários finais (seção 5).

\section{Atenuação da luz}

Para se representar a atenuação da energia luminosa em meios materiais, é preciso explorar modelos que capturam os processos de absorção e espalhamento responsáveis por atenuar a energia luminosa ao atravessar esses meios. A seguir explicamos como esses mecanismos funcionam e citamos os principais modelos usados para descrevê-los.

O processo de absorção da luz se caracteriza pela transferência da energia eletromagnética para a matéria. Quando a luz é absorvida por um material, sua energia pode ser convertida em energia cinética ou potencial do sistema. Depois de ser excitado, o elétron pode retornar espontaneamente para um estado mais estável, emitindo um fóton em direção arbitrária ${ }^{3}$ Dessa forma, apesar do processo de absorção extinguir o fóton incidente, existe a possibilidade da radiação voltar ao meio pela emissão espontânea, mas geralmente sua direção de propagação, ou mesmo sua energia, não é mantida esse fato contribui para a atenuação da luz e será incorporado no modelo de Beer-Lambert [25], que discutiremos na seção 2.2 .

Outro processo relevante para descrever a atenuação da luz é o espalhamento, que consiste na mudança de direção de propagação da luz por conta da sua interação com a matéria. Esse fenômeno pode ocorrer de forma inelástica ou elástica, isto é, com ou sem

\footnotetext{
${ }^{3}$ Esse processo ocorre em contraste com a emissão estimulada, presente nos lasers. Nessa situação, um fóton é emitido por um átomo ou molécula - quando um elétron faz a transição de um estado excitado para um mais estável — de forma a manter a direção $e$ sentido de propagação da radiação incidente (além de manter sua fase, energia e polarização). A emissão é dita estimulada porque esse processo se inicia com um fóton e termina com dois, enquanto a emissão espontânea conserva o número de fótons. Apesar de ocorrer naturalmente, a emissão estimulada não é o efeito dominante quando comparado com a emissão espontânea, pois requer que os elétrons estejam em níveis de energia mais altos, o que não acontece nas situações típicas de equilíbrio térmico.
} 
perda de energia. Quando se trata do espalhamento da luz visível, alvo do nosso estudo, destacam-se os tipos elásticos de espalhamento, pois perdas significativas de energia na interação entre a radiação e a matéria só são relevantes nas situações envolvendo altas energias. Descrições detalhadas envolvem, em geral, múltiplos parâmetros e são complicadas, pois requerem o cálculo da direção de espalhamento e a energia da luz espalhada. Como exemplo de espalhamento elástico da luz, pode ser citado o modelo teórico de espalhamento Rayleigh, que representa situações em que o comprimento de onda da radiação incidente é muito maior [26] do que o tamanho das partículas do meio. Esse modelo prevê que a intensidade do feixe espalhado é inversamente proporcional à quarta potência do comprimento de onda da radiação incidente sobre as partículas do meio, podendo ser espalhado em todas as direções, porém com maior intensidade ao longo do eixo formado pela direção da radiação incidente. Outros exemplos importantes de espalhamentos elásticos são os espalhamentos de Thomson e Mie, que descrevem o espalhamento da luz por partículas livres carregadas e por partículas esféricas cujo tamanho é comparável ao comprimento de onda da radiação incidente, respectivamente.

Apesar de fornecer conhecimentos significativos, o poder preditivo desses modelos dificilmente pode ser aferido em nível quantitativo por meio do processo de contrastação empírica em laboratórios didáticos, dado o elevado grau de particularização das suas hipóteses. Essa constatação nos motiva a adotar a Lei de Beer-Lambert visto que, como veremos, ela incorpora os mecanismos de atenuação da luz (absorção e espalhamento) com a vantagem de ser mais facilmente contrastável empiricamente. A seguir, com o objetivo de relembrar ou familiarizar o leitor com os conceitos fundamentais da Fotometria - essenciais para entender a atenuação da luz visível e os instrumentos de medida utilizados na investigação - apresentamos um panorama sobre essa área, bem como o mínimo necessário para a presente discussão sobre a fisiologia do olho humano.

\subsection{Alguns conceitos básicos de radiometria e fotometria}

Ao lidar com atenuação luminosa, é fundamental fazer distinção entre Fotometria e Radiometria. A Radiometria estuda o espectro eletromagnético completo, enquanto a Fotometria se limita ao estudo do espectro da luz visível, sendo por isso definida em termos da sensibilidade do olho humano. Apesar de existir sensores capazes de medir a intensidade da energia eletromagnética em faixas fora do visível, todos se concentram na mensuração de uma faixa específica do espectro ${ }^{4}$ Isso ocorre porque os sensores óticos funcionam baseados no princípio da ressonância com a onda eletromagnética

\footnotetext{
4 Por exemplo, alguns sensores medem apenas em uma faixa do infravermelho, outros apenas em uma faixa do ultravioleta, etc.
}

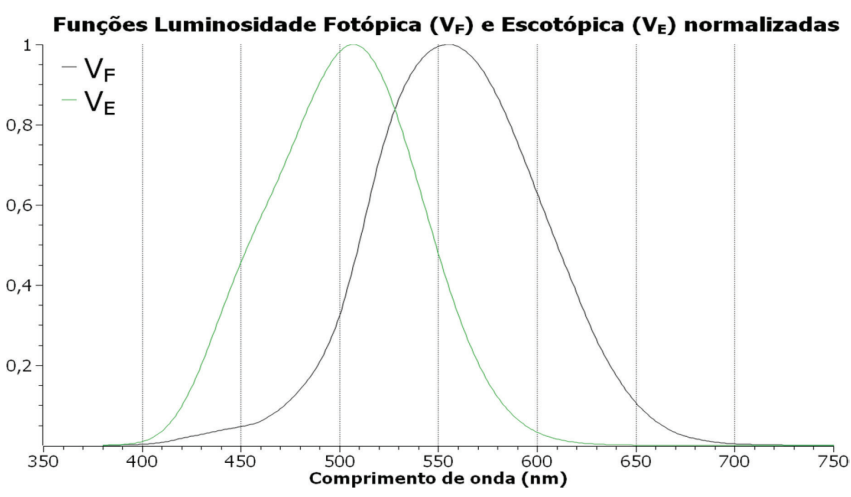

Figura 1: Sensibilidade espectral do olho humano [27].

a ser detectada, de forma que apenas uma banda de frequências pode ser medida em cada tipo de detector. A principal vantagem em considerar apenas a componente visível da radiação é que temos à disposição instrumentos de medida que operam ao longo de toda essa faixa, ignorando o restante. Tais instrumentos levam em consideração não apenas a faixa sensível ao olho humano, mas também a fisiologia desse órgão, incorporando sua sensibilidade espectral na medição. Por isso vamos discorrer brevemente sobre esse assunto.

Dependendo das condições de luminosidade do ambiente, o olho humano tem um pico de sensibilidade em torno de certo comprimento de onda. Geralmente, para situações de baixa intensidade luminosa, tem-se a visão chamada Escotópica, com pico de sensibilidade em torno de $507 \mathrm{~nm} 5$ enquanto em condições de maior luminosidade, tem-se a visão Fotópica, com pico de sensibilidade em torno de $555 \mathrm{~nm}$. A chamada Função Luminosidade, representada por $V(\lambda)$, descreve a sensibilidade espectral do olho humano, estando representada na Figura 1. As funções $V_{E}(\lambda)$ e $V_{F}(\lambda)$ representam as funções Escotópicas e Fotópicas, respectivamente, normalizadas a 1 nos picos de sensibilidade do olho humano.

Em Física - e em particular na Radiometria - definimos a grandeza fluxo radiante $\Phi_{e}$ como a potência eletromagnética total que atravessa uma superfície $A$. Da Teoria Eletromagnética, podemos obter essa grandeza através do Vetor de Poynting $\vec{S}$ :

$$
\Phi_{e}=\int_{A} \vec{S} \cdot d \vec{A}
$$

em que $d \vec{A}$, diferencial do vetor área, é um vetor perpendicular à área de integração cujo módulo é igual a essa área, $[\vec{S}]=W / m^{2}$ e $\left[\Phi_{e}\right]=W$ (Watts). Geralmente, uma fonte de radiação eletromagnética emite luz em um espectro contínuo, mas o olho humano percebe apenas

\footnotetext{
5 As células do olho responsáveis por detectar essas radiações se chamam bastonetes.

6 Nesse caso, as células se chamam cones e são as responsáveis pela nossa percepção de cores.
} 
radiações com comprimentos de onda entre aproximadamente $400 \mathrm{~nm}$ e $700 \mathrm{~nm}$, e não com a mesma sensibilidade em todo esse intervalo. Uma grandeza física que leva em consideração apenas a potência visível ao olho humano é o fluxo luminoso $\Phi_{V}$. Isso é feito através da ponderação, baseada na Função Luminosidade $V(\lambda)$, da sensibilidade do olho humano aos comprimentos de onda de um feixe de luz com uma certa distribuição espectral $\Phi_{e}(\lambda)$. O fluxo luminoso que atravessa uma superfície pode ser calculado através de:

$$
\Phi_{V}=683 \frac{\operatorname{lm}}{W} \int_{0}^{\infty} V(\lambda) \Phi_{e}(\lambda) d \lambda .
$$

A unidade do fluxo luminoso é o lúmen $(\mathrm{lm})$, isto é, $\left[\Phi_{V}\right]=l m$. A unidade lúmen pode ser definida da seguinte forma: uma fonte luminosa emitindo um fluxo radiante $\Phi_{e}$ de $1 \mathrm{~W}$ em um comprimento de onda de $555 \mathrm{~nm}$ (pico da Função Luminosidade Fotópica) gera um fluxo luminoso de 683 lúmens7 A unidade lúmen é utilizada, por exemplo, quando comparamos a luminosidade de lâmpadas ou projetores, sendo uma das especificações técnicas desse tipo de aparelho. É importante compreender que o fluxo luminoso é uma grandeza relacionada à percepção do olho humano, podendo variar levemente de indivíduo para indivíduo. Felizmente, não precisamos lidar diretamente com a Equação 2 Assumindo um padrão para a Função Luminosidade, temos à disposição aparelhos eletrônicos — como um luxímetro ou nosso próprio celular - com sensores capazes de medir o fluxo luminoso que entra no instrumento de medida. De maneira mais precisa, o que esses aparelhos medem é a grandeza chamada iluminância $\left(E_{V}\right)$, definida como o fluxo luminoso $\Phi_{V}$ incidente em uma superfície de área $A$, por unidade de área:

$$
E_{V}=\frac{\Phi_{V}}{A}
$$

onde a unidade de medida no SI é o lux (lx), isto é, $\left[E_{V}\right]=l x$, sendo $1 l x=\frac{l m}{m^{2}}$. A iluminância é uma grandeza importante, por exemplo, na Astronomia, estando relacionada ao brilho (ou magnitude aparente) dos astros no céu.

Partindo dos conceitos apresentados, vamos proceder à expansão do modelo teórico de propagação da luz. Primeiro exploramos o modelo de propagação da luz no vácuo considerando dois casos: uma fonte que produz um feixe de luz colimado, com propagação retilínea, e uma fonte pontual, que emite feixes de luz radiais. Analisaremos as implicações físicas e limitações desses modelos,

\footnotetext{
7 A partir dessa definição, entende-se de onde vem o fator 683 na Equação 2 A definição mais formal, utilizando a candela uma das sete grandezas fundamentais do SI — pode ser expressa da seguinte forma: um lúmen é definido como o fluxo luminoso produzido por uma fonte luminosa que emite uma candela $(\mathrm{Cd})$ de Intensidade Luminosa em um ângulo de um esterradiano (Sr). Evitamos expressar a unidade nesses termos porque ainda não definimos o conceito de Intensidade Luminosa nem introduzimos a unidade candela.
}

destacando as idealizações e aproximações assumidas. A seguir, incorporamos os efeitos da atenuação da luz devido à absorção e espalhamento, culminando em um modelo expandido por meio do uso da Lei de BeerLambert, que doravante denominaremos apenas por modelo de Beer-Lambert.

\subsection{Expansão do modelo de propagação da luz no vácuo}

Considere uma fonte luminosa que produz um feixe de luz colimado. Que tipo de fonte poderia ser considerada colimada? Um laser, por exemplo, emite um feixe de luz com uma abertura angular típica de $1,2 \times 10^{-3} \mathrm{rad} \approx$ $0,068^{\circ}$, o que corresponde em um círculo luminoso projetado, a $10 \mathrm{~m}$ de distância, de apenas $1,2 \mathrm{~cm}$ de diâmetro. Desta forma, nas distâncias usuais de laboratório, como a cintura do feixe de um laser é aproximadamente constante, costuma-se considerar seu feixe de luz como colimado. Trabalhando com essas idealizações na situação de vácuo, a iluminância $E_{V}$ medida na ponteira do laser (isto é, o fluxo luminoso que entra no sensor por unidade de área) deve ser a mesma medida a uma distância $x$ qualquer. Assim, assumindo que o alinhamento entre o laser e o luxímetro seja mantido, tem-se:

$$
E_{V}(x)=E_{V}
$$

De fato, um feixe de laser pode se propagar por longas distâncias, como ficou evidente em um experimento em que astronautas da estação espacial internacional, distante cerca de $400 \mathrm{~km}$ da superfície terrestre, conseguiram observar um feixe de laser de 1 Watt provindo da Terra 8 Cabe destacar que a discussão é válida não apenas para lasers, mas para qualquer fonte colimada.

Outro tipo de fonte luminosa de interesse é uma fonte que emite luz radialmente em todas as direções com a mesma intensidade, ou seja, uma fonte de luz isotrópica, comumente idealizada como fonte pontual isotrópica. Que tipo de fonte luminosa real pode ser considerada como aproximadamente pontual isotrópica? Qualquer objeto pode ser considerado pontual desde que a distância até ele seja grande. Considere o Sol, por exemplo: na escala do sistema solar, costumamos considerá-lo como uma fonte pontual isotrópica de luz. Uma vela acesa, por outro lado, apesar de poder ser considerada uma fonte de luz pontual se analisada de uma distância suficientemente grande, dificilmente poderá ser considerada isotrópica, já que sua chama possui simetria axial ao longo do pavio. Considerando uma fonte pontual isotrópica no vácuo emitindo um fluxo luminoso $\Phi_{V}$, podemos obter a iluminância a uma distância $r$ assumindo que a energia luminosa se propaga de tal modo

\footnotetext{
8 Amateur Astronomers Flash the Space Station. Disponível em: https://www.universetoday.com/93987/amateur-astronomers-fla sh-the-space-station/, Acesso em: 05/05/2020.
} 
que, a uma distância $r$, toda a energia luminosa da fonte se distribui uniformemente sobre a área $A$ de uma esfera dada por $A=4 \pi r^{2}$. Portanto, temos:

$$
E_{V}(r)=\frac{\Phi_{V}}{4 \pi r^{2}}
$$

Diferentemente da Equação 4 que não prevê alteração na iluminância com a distância, a Equação 5 prevê uma queda quadrática em função da distância da fonte pontual. Essa queda, entretanto, tem relação com a distribuição da luz sobre uma área cada vez maior com a distância, não com à absorção ou espalhamento pelo meio.

Para incluir os efeitos de absorção e espalhamento para essas duas situações - feixe colimado e fonte pontual — vamos fazer uma dedução baseada na Lei de Beer-Lambert.

\subsubsection{Fonte colimada}

Considere uma fonte de luz que emite um feixe colimado, incidindo perpendicularmente em uma seção de comprimento " $d x$ " de um material, conforme a Figura 2 Ao atravessar a região de espessura $d x$, a luz interage com os elementos constituintes do material, representados por círculos escuros na figura. Aqui usamos a denominação genérica "elementos" para representar átomos ou moléculas.

Na representação da Figura 2, a luz pode ser absorvida ou espalhada quando incide sobre um elemento. Passamos a assumir as seguintes idealizações com relação a essa situação:

1. A reemissão de luz, decorrente da absorção, não contribui para o feixe original.

2. A luz espalhada não volta a contribuir com o feixe original.

3. Meio material é homogêneo e não é alterado pela incidência de luz.

Essas idealizações se referem tanto ao material, quanto à dinâmica da interação da radiação com a matéria. A primeira delas despreza a possibilidade de que a luz absorvida possa voltar ao sistema. Como vimos, a radiação pode voltar por meio da emissão espontânea, tendo assim a chance de ser detectada mais à frente. Já a segunda, desconsidera o fato de que a luz possa sofrer múltiplos espalhamentos ao longo de seu percurso, de

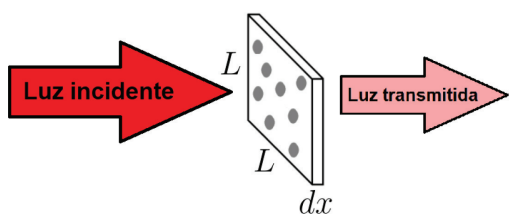

Figura 2: Luz colimada incidindo normalmente em uma seção do material. A luz transmitida tem intensidade menor que a incidente. forma que, eventualmente, volte a se propagar na e sentido original depois de interagir várias vezes com os elementos do material. Assumir que a radiação não volta a se propagar no seu sentido inicial significa admitir que, depois de desviada, não será detectada pelo luxímetro: compreender esse pressuposto é fundamental, principalmente quando lidamos com meios que espalham muito a luz, situação na qual essa idealização é pouco razoável. Já a terceira idealização pressupõe que o número de elementos por unidade de volume seja o mesmo ao longo de todo o material. Assume-se também que o feixe de luz não tem energia suficiente para mudar as propriedades do meio, desintegrando moléculas, por exemplo. É fundamental ter em mente essas idealizações, pois o delineamento experimental e a análise dos dados serão guiadas por elas. A partir de agora, derivamos conclusões a partir das idealizações assumidas.

Considerando a área da seção de material como $L^{2}$, o número de elementos dentro da seção de comprimento $d x$ pode ser obtido pela expressão $n L^{2} d x$, onde $n$ é o número de elementos por unidade de volume do material $\left([n]=m^{-3}\right)$. A probabilidade $d p$ da luz do feixe incidente interagir com algum elemento da seção de material sofrendo absorção ou espalhamento - é igual à fração da área do material ocupada pelos mesmos, ou seja, é igual à razão entre a soma das áreas dos elementos confinados no paralelepípedo de lado $L^{2}$ e largura $d x$ (veja na Figura 2) e a área total $L^{2}$ da lateral deste paralelepípedo:

$$
d p=\frac{\sigma n L^{2} d x}{L^{2}}=\sigma n d x,
$$

onde $\sigma$ é a "área" de um elemento do material, isto é, sua seção de choque transversa ${ }^{9}$ Esse parâmetro pode ser escrito como a soma da seção de choque de absorção e espalhamento, porém optamos por explicitar essa distinção no coeficiente de atenuação, definido mais adiante. Mesmo que o material fosse composto por vários elementos, cada um com diferentes áreas e densidades, ainda poderíamos escrever a Equação 6 somando suas contribuições individuais por meio de uma seção de choque equivalente/efetiva dada por $\sigma=\sigma_{1} n_{1}+\sigma_{2} n_{2}+$ ... A Equação 6 indica que as interações da luz com a matéria nas diferentes camadas do material são eventos independentes, já que a chance de interação depende apenas das propriedades do meio $(\sigma$ e $n)$. A mudança $d E_{V}$ na iluminância $\left(E_{V}\right)$ que entra na seção de espessura $d x$ do material depende justamente de $d p$, tal que:

$$
d E_{V}=-E_{V} d p=-E_{V} \sigma n d x .
$$

O sinal negativo se justifica porque a iluminância diminui quando a luz interage com a matéria. Essa equação diferencial ordinária pode ser resolvida por meio da sua integração em algum intervalo de comprimento

\footnotetext{
9 Deve-se ter cuidado com a expressão "do material", já que, assim como o índice de refração "dos materiais", a seção de choque depende do comprimento de onda incidente, isto é, $\sigma=\sigma(\lambda)$.
} 
$[0, x]$ de material. Considerando que $E_{V}(x=0)=E_{V_{0}}$, obtém-se a expressão:

$$
\begin{aligned}
\int_{E_{V_{0}}}^{E_{V}} \frac{d E_{V}}{E_{V}} & =-\sigma n \int_{0}^{x} d x \Rightarrow \ln \left(E_{V}\right)-\ln \left(E_{V_{0}}\right)=-\sigma n x \\
E_{V}(x) & =E_{V_{0}} e^{-\sigma n x}
\end{aligned}
$$

Essa é a conhecida lei de Beer-Lambert 25]. Pelo sinal negativo no expoente, deve haver uma diminuição exponencial na iluminância ao longo do caminho ótico percorrido pela luz, sendo que a seção de choque transversal e a densidade do material têm forte influência nesse processo. Apesar da extinção da radiação ao longo de seu percurso pelo meio material acontecer de maneira não determinística, pode-se calcular a distância média $\bar{x}$ percorrida pela luz antes de sofrer absorção ou espalhamento através do valor esperado (ou simplesmente a média) da posição onde esses eventos ocorrem. Para realizar esse cálculo, precisamos conhecer a probabilidade $d p^{\prime}$ da luz ser absorvida ou espalhada ao longo de todo material, o que pode ser feito, de maneira análoga à Equação 6, calculando a fração (positiva) de luz extinta $\left|d E_{V}\right|$ em cada ponto do material em relação à iluminância inicial $E_{V_{0}}$ :

$$
d p^{\prime}=\frac{\left|d E_{V}\right|}{E_{V_{0}}} .
$$

Derivando a Equação 8 e substituindo na Equação 9 tem-se:

$$
d p^{\prime}=\sigma n e^{-\sigma n x} d x
$$

A Equação 10 indica que a probabilidade de interação da luz com a matéria (por meio de absorção ou espalhamento) diminui com a distância, pois a iluminância diminui à medida que a luz passa pelo meio. Dessa forma, considerando $x$ uma variável aleatória que especifica a posição onde a luz é extinta e $d p^{\prime}$ a probabilidade da mesma ser extinta no intervalo $[x, x+d x]$, podemos calcular a média de $x$, isto é, $\bar{x}$, através da definição do valor esperado de uma variável aleatória:

$$
\begin{aligned}
\bar{x} & =\int_{0}^{\infty} x d p^{\prime}=\sigma n \int_{0}^{\infty} x e^{-\sigma n x} d x \\
& =\sigma n\left(-\left.\frac{x e^{-\sigma n x}}{\sigma n}\right|_{0} ^{\infty}+\frac{1}{\sigma n} \int_{0}^{\infty} e^{-\sigma n x} d x\right) \\
\bar{x} & =\frac{1}{\sigma n} .
\end{aligned}
$$

Ou seja, em média, a luz é espalhada ou absorvida em torno da posição $(\sigma n)^{-1}$. Comumente, essa grandeza é denominada livre caminho médio, ou distância de atenuação $D$, isto é:

$$
D=\frac{1}{\sigma n}
$$

Então, podemos reescrever a Lei de Beer-Lambert (Equação 8) como:

$$
E_{V}(x)=E_{V_{0}} e^{-x / D}=E_{V_{0}} e^{-\mu x},
$$

em que $\mu=1 / D$ é chamado de coeficiente de atenuação linear ${ }^{10}$ que quantifica a capacidade do meio em absorver ou espalhar a radiação que passa através dele, de forma que, quanto maior esse valor, maior é a extinção da luz ao atravessá-lo e, portanto, menor seu livre caminho médio.

Em síntese, enquanto a iluminância produzida por um feixe de luz colimada não se altera com a distância no vácuo, espera-se um decaimento exponencial a partir de $E_{V_{0}}$ quando a luz atravessa um meio material que possui coeficiente de atenuação linear $\mu$ para o(s) comprimento(s) de onda da radiação incidente. Na literatura, é comum fazer a distinção entre o coeficiente de absorção $\mu_{A}$ e espalhamento $\mu_{E}$, de forma que o coeficiente de atenuação linear é a soma $\mu=\mu_{A}+\mu_{E}$. Existem instrumentos sofisticados [28] capazes de medir tais grandezas isoladamente, porém, com os instrumentos didáticos disponíveis em laboratórios de ensino, comumente só conseguimos determinar a atenuação total da luz levando em consideração ambos os efeitos.

\subsubsection{Fonte pontual}

Para expandir o modelo de emissão de luz por uma fonte pontual, abarcando a atenuação da luz pelo meio, considere a Figura 3, onde uma fonte pontual isotrópica está imersa em um meio atenuante, como o ar, por exemplo.

Diretamente das definições de iluminância (Equação 3) e de ângulo sólido, pode-se afirmar que um sensor de luxímetro com área $A$ colocado a uma distância $r$ de uma fonte pontual mede uma iluminância dada por:

$$
E_{V}=\frac{\Phi_{V}}{A}=\frac{\Phi_{V}}{\Omega r^{2}}
$$

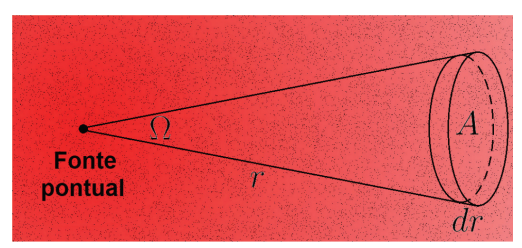

Figura 3: Fonte pontual imersa em um meio material. A luz contida no ângulo sólido $\Omega$ atravessa a área $A$ caso não seja absorvida ou espalhada pelo meio. A luz fora do ângulo sólido pode atravessar a área caso sofra espalhamentos múltiplos, porém esse efeito não é considerado pelo modelo.

\footnotetext{
10 É comum utilizar o coeficiente de atenuação mássico (unidade igual a $\mathrm{m}^{2} / \mathrm{kg}$ ) em vez de coeficiente linear. Para converter do coeficiente de atenuação mássico para o linear, basta multiplicá-lo pela densidade do meio.
} 
onde $\Phi_{V}$ é o fluxo luminoso que saiu da fonte pelo ângulo sólido $\Omega$. Nessa equação, a área do elemento de ângulo sólido indicado na Figura 3 é $A=\Omega r^{2}$. À medida que a luz se propaga, a iluminância diminui tanto pela sua absorção e espalhamento pelo meio material, como também pela distribuição da radiação por uma área maior. Por isso, para descrever a variação da iluminância em função do fluxo luminoso $\Phi_{V}$ e da distância $r$, tomase o diferencial total da Equação 14, considerando o ângulo sólido $\Omega$ constante:

$$
\begin{aligned}
d E_{V} & =\frac{\partial}{\partial \Phi_{V}}\left(\frac{\Phi_{V}}{\Omega r^{2}}\right) d \Phi_{V}+\frac{\partial}{\partial r}\left(\frac{\Phi_{V}}{\Omega r^{2}}\right) d r \\
d E_{V} & =\frac{d \Phi_{V}}{\Omega r^{2}}-\frac{2 \Phi_{V} d r}{\Omega r^{3}} .
\end{aligned}
$$

Neste ponto, pode-se fazer uma dedução análoga ao caso de fonte de luz colimada. A probabilidade da luz ser absorvida ou espalhada ao passar pelo elemento de volume $d V=A d r$ na Figura 3 é igual à fração da área $A$ que é ocupada por elementos do meio material, ou seja, pode ser calculada como na Equação 6, isto é:

$$
d p=\frac{\sigma n A d r}{A}=\sigma n d r=\mu d r,
$$

onde se utilizou o resultado da Equação 13 para escrever o coeficiente de atenuação linear $\mu$. Assim, de maneira análoga à Equação 7] a variação do fluxo luminoso ao atravessar o volume $d V$ pode ser calculada pela expressão $d \Phi_{V}=-\Phi_{V} d p=-\Phi_{V} \mu d r$. Utilizando esse resultado na Equação 15 , tem-se:

$$
d E_{V}=\frac{-\Phi_{V}}{\Omega r^{2}}\left[\mu+\frac{2}{r}\right] d r .
$$

Observe que o termo fatorado é a iluminância no ponto onde está o detector, conforme a Equação 14 Logo:

$$
\begin{aligned}
d E_{V} & =-E_{V}\left[\mu+\frac{2}{r}\right] d r, \\
\int_{?}^{E_{V}} \frac{d E_{V}}{E_{V}} & =-\mu \int_{?}^{r} d r-2 \int_{?}^{r} \frac{d r}{r} .
\end{aligned}
$$

Repare que os limites de integração da primeira e terceira integral são um problema, já que, pela definição expressa na Equação 14 a iluminância a uma distância $r=0$ (na fonte) é infinita e a solução da integral diverge nesses limites. Por isso, para realizar a integração, é conveniente escolher uma distância inicial $r_{0}$ tal que a atenuação da luz seja desprezível. Nessa distância, conforme representado na Figura 4, a iluminância é $E^{\prime} V$.

Tomando-se $r_{0}$ e $E^{\prime}{ }_{V}$ como os limites inferiores de integração na Equação 16, tem-se:

$$
\begin{aligned}
\int_{E_{V}^{\prime}}^{E_{V}} \frac{d E_{V}}{E_{V}} & =-\mu \int_{r_{0}}^{r} d r-2 \int_{r_{0}}^{r} \frac{d r}{r} \\
\ln \left(\frac{E_{V}}{E_{V}^{\prime}}\right) & =-\mu\left(r-r_{0}\right)-2 \ln \left(\frac{r}{r_{0}}\right), \\
E_{V} & =\frac{E_{V}^{\prime} r_{0}^{2}}{r^{2}} e^{-\mu\left(r-r_{0}\right)} .
\end{aligned}
$$

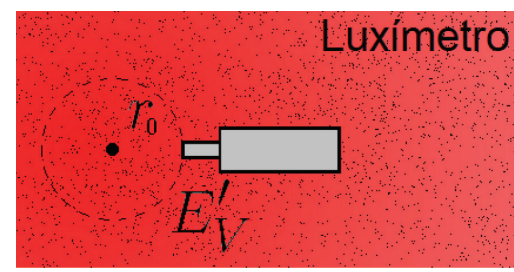

Figura 4: A iluminância medida pelo luxímetro a uma distância $r_{0}$ é $E^{\prime}{ }_{V}$. Como a fonte é idealmente pontual, podemos considerar $r_{0}$ tão pequeno quanto se deseja.

Essa equação pode ser escrita de forma mais elegante em termos do fluxo luminoso $\Phi_{V_{0}}$ emitido pela fonte pontual. Para fazer isso, considere o limite da Equação 17 para $r_{0} \rightarrow 0$. Aproximando o ponto $r_{0}$ da fonte, podemos escolhê-lo tão pequeno quanto necessário para que não haja atenuação significativa da luz para essas distâncias. Nessa situação, aproximamos a iluminância $E_{V}^{\prime}$ por meio do modelo de propagação da luz no vácuo, isto é:

$$
E^{\prime}{ }_{V}=\frac{\Phi_{V_{0}}}{4 \pi r_{0}^{2}}
$$

de forma que a Equação 17 se torna:

$$
E_{V}(r)=\frac{\Phi_{V_{0}}}{4 \pi r^{2}} e^{-\mu r} .
$$

Portanto, enquanto no vácuo a iluminância produzida por uma fonte pontual diminui com o inverso do quadrado da distância, quando a luz atravessa um meio material que possui coeficiente de atenuação linear $\mu$, espera-se, nesse modelo expandido, um decaimento exponencial com o afastamento da fonte.

\subsubsection{Episódio de Modelagem sobre atenuação da luz}

Iniciamos detalhando as quatro etapas deste Episódio de Modelagem.

Tarefa prévia: o estudante deve se preparar para a primeira aula do EM realizando, por ex., a leitura de um texto e respondendo três ou quatro questões, cujas respostas são enviadas para o professor até $24 \mathrm{~h}$ antes da aula. Essas tarefas visam: $i$. a mobilização, por parte dos estudantes, de conhecimentos relevantes tanto para a compreensão da situação-problema como para o enfrentamento dela; e ii. a ciência, por parte do professor, das dificuldades dos estudantes a fim de poder auxiliá-los a superá-las. Neste EM, indicamos a leitura de um texto elaborado especialmente para essa atividade [11 [24, em que são apresentados conceitos fundamentais de fotometria (subseção 2.1 deste artigo), assim como a leitura de algumas seções do livro adotado na disciplina, Halliday\&Resnick [29] para relembrá-los ou

\footnotetext{
11 Todos os materiais elaborados para este EM estão disponíveis na referência 24].
} 
Quadro 1: Síntese dos modelos teóricos construídos. Nosso foco está na grandeza física iluminância porque nas investigações apresentadas na próxima seção, são usados luxímetros, instrumentos que medem iluminância.

\begin{tabular}{|c|c|c|c|}
\hline \multicolumn{2}{|c|}{ Tipo de fonte } & Colimada & Pontual \\
\hline \multicolumn{2}{|c|}{ Teoria Geral } & \multicolumn{2}{|c|}{ Teoria Eletromagnética (Ótica Geométrica e Ótica Física) } \\
\hline \multirow{2}{*}{$\begin{array}{l}\text { Modelo Teórico de } \\
\text { propagação no vácuo }\end{array}$} & Idealizações & $\begin{array}{l}\text { Propagação da luz retilínea; } \\
\text { Feixes de luz paralelos. }\end{array}$ & $\begin{array}{l}\text { Propagação da luz isotrópica; } \\
\text { Feixes de luz radiais. }\end{array}$ \\
\hline & $\begin{array}{l}\text { Representação } \\
\text { matemática da } \\
\text { iluminância }\end{array}$ & $E_{V}(x)=E_{V}$ & $E_{V}(r)=\frac{\Phi_{V}}{4 \pi r^{2}}$ \\
\hline \multirow{2}{*}{$\begin{array}{l}\text { Modelo Teórico de } \\
\text { propagação em meios } \\
\text { materiais }\end{array}$} & $\begin{array}{l}\text { Idealizações incorporadas } \\
\text { no processo de expansão }\end{array}$ & \multicolumn{2}{|c|}{$\begin{array}{l}\text { A reemissão de luz, decorrente da absorção, não contribui para o feixe original. } \\
\text { A luz espalhada não volta a contribuir com o feixe original. } \\
\text { Meio material é homogêneo e não é alterado pela incidência de luz. }\end{array}$} \\
\hline & $\begin{array}{l}\text { Representação } \\
\text { matemática da } \\
\text { iluminância }\end{array}$ & $E_{V}(x)=E_{V_{0}} e^{-\mu x}$ & $E_{V}(r)=\frac{\Phi_{V_{0}}}{4 \pi r^{2}} e^{-\mu r}$ \\
\hline
\end{tabular}

familiarizá-los com o conceito de vetor de Poynting e o modelo de propagação da luz no vácuo.

Discussão inicial: a situação-problema é apresentada em uma exposição dialogada, de não mais de uma hora de duração, levando em conta as respostas fornecidas pelos estudantes na tarefa prévia. São apresentadas três possibilidades de experimentos, porém os estudantes podem propor seus próprios experimentos, desde que sejam factíveis com os materiais disponíveis no laboratório ou que eles se encarreguem de providenciá-los. A descrição dos três experimentos propostos constam na seção 3 deste artigo. Finalizada a apresentação do professor, os estudantes, divididos em grupos decidem que investigação pretendem fazer e começam o planejamento do experimento que será feito na aula seguinte.

Investigações: nesta etapa, ocorre a parte prática do EM, isto é, a montagem do aparato experimental, coleta de dados e início da análise. Os grupos só são autorizados a coletar os dados depois de o professor aprovar o delineamento experimental planejado e descrito em seus cadernos de laboratório. No exame do planejamento, o professor averigua, por exemplo, quais variáveis serão medidas e de que forma; que fatores serão controlados e de que forma; como está planejada a contrastação entre os resultados previstos pelo modelo teórico e as evidências.

Discussão final: os grupos descrevem ${ }^{12}$ para os outros integrantes da turma as suas soluções, buscando trazer os aspectos essenciais que guiaram a sua investigação. Nessa etapa, ocorrem discussões entre os vários grupos, quer porque são comparados os resultados obtidos para um mesmo experimento, quer para experimentos distintos. Então, o professor faz uma síntese final.

Os experimentos apresentados na próxima seção tratam de investigações com feixes de luz gerados por laser ou por fontes pontuais, que se propagam em algum meio. Será empregado o modelo de propagação da luz no vácuo expandido com a inclusão de efeitos do meio (absorção e espalhamento) sobre o feixe, ou

\footnotetext{
12 As apresentações são feitas em pequenos quadros brancos $\left(\sim 1 \mathrm{~m}^{2}\right)$.
}

seja, expandido com a Lei de Beer-Lambert. Buscando ressaltar o processo de modelagem científica construído nesta seção, sintetizamos alguns elementos chave no Quadro 1] que explicita os modelos de propagação da luz no vácuo e em meios materiais para os dois tipos de fontes analisadas.

Todas as medidas de iluminância foram feitas com um luxímetro com sensibilidade espectral na região do visível. A incerteza do instrumento varia de acordo com a escala; em nossas medições seu valor foi 0,1 lux ou 0,1 klux. Como um procedimento padrão do controle de variáveis, buscamos realizar todas as investigações no escuro, já que se assume que a luz detectada pelo luxímetro provém unicamente da fonte. Outro procedimento essencial de controle de variáveis realizado em todos os experimentos diz respeito ao alinhamento entre o sensor do luxímetro e a fonte emissora de luz: tanto nas situações de fonte colimada quanto pontual, é essencial dispor o luxímetro de forma que haja incidência normal da luz na superfície de detecção do sensor. Procedimentos específicos para cada uma das investigações serão discutidos ao longo do delineamento experimental exposto na próxima seção. Além disso, em todos os experimentos considerados neste artigo assume-se que a luz absorvida não é mais reemitida. Se o for (por emissão espontânea), as chances são baixas de que a direção e sentido de propagação da radiação coincida com a da luz anteriormente absorvidas, conforme foi discutido.

\section{O processo de contrastação empírica}

A situação-problema suscitada na discussão inicial do EM lançou o seguinte desafio para os alunos:

Como se dá a atenuação da energia luminosa ao atravessar meios materiais? Como a poluição dos oceanos pode influenciar a fotossíntese das algas por meio de alterações na atenuação da luz solar?

Para responder a essas perguntas, fez-se necessário expandir o modelo de propagação da luz no vácuo, incorporando os efeitos da atenuação da luz, o que foi feito por meio do uso da Lei de Beer-Lambert. Para aferir a capacidade desse modelo teórico em gerar 
previsões confiáveis, vamos submetê-lo ao processo de contrastação empírica. Conforme mencionado anteriormente, três opções investigativas são propostas, cada uma buscando avaliar a atenuação da luz em diferente meios (vidro, solução de água + sal e fumaça). Nas próximas subseções, apresentamos essas investigações detalhadamente, comparando as previsões do modelo de propagação da luz no vácuo com do modelo de propagação da luz em meios materiais frente aos dados experimentais coletados. Além disso, buscamos apontar a influência de fatores não levados em consideração no modelo, procurando destacar a importância do papel do controle de variáveis no delineamento experimental.

\subsection{Atenuação da luz nos sólidos}

A seguinte investigação é proposta pelo professor:

Um laser é uma fonte monocromática, isto é, uma fonte de luz que emite luz em apenas um comprimento de onda $\lambda_{L}$. Avalie a atenuação da energia luminosa de um laser em um meio sólido como o vidro.

Para realizar a investigação, os alunos têm à disposição varetas de vidro de diferentes comprimentos, mas mesmo diâmetro, luxímetros, lasers, cavaleiros, trilhos e suportes. Buscando avaliar a atenuação luminosa nesse meio, incidimos a luz de um laser $(670 \mathrm{~nm})$ diretamente sobre uma face da vareta de vidro e medimos a iluminância imediatamente na face oposta, com a montagem experimental da Figura 5

Avaliando esta montagem experimental do ponto de vista das idealizações assumidas no modelo teórico de propagação da luz em meios materiais para fontes colimadas (veja Quadro 1) - admitimos que o laser é uma fonte colimada - vemos que: i) a idealização de que a luz espalhada não é mais detectada pelo luxímetro não é totalmente satisfeita, porque as barras de vidro são finas, propiciando o aprisionamento da radiação por meio da reflexão total; e ii) a idealização sobre a homogeneidade do meio é consideravelmente satisfeita, pois os vidros são aproximadamente isotrópicos.

As varetas de vidro utilizadas na investigação foram fabricadas na vidraria da universidade por meio da

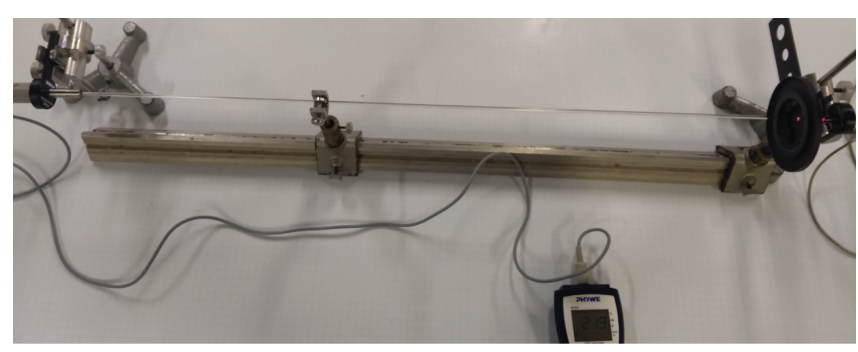

Figura 5: A vareta de vidro é apoiada sobre um trilho. O luxímetro está posicionado na sua face esquerda; o laser, na direita. Entre o laser e a vareta, foi colocada uma placa metálica com um furo circular de diâmetro equivalente ao da vareta, para impedir que luz que passe por fora da vareta chegue ao luxímetro. técnica de corte tradicional, onde o vidro é quebrado depois de sofrer um risco. A seção transversal exposta pelo corte foi então polida para minimizar a incidência oblíqua da luz; mesmo assim, a textura da superfície que sofreu o corte não ficou lisa como o vidro de uma janela. A rugosidade da interface ar-vidro pode afetar a iluminância medida tanto por mudar a direção de propagação da luz, quanto por diminuir a quantidade de energia que entra na vareta, já que o ângulo de incidência da luz afeta a quantidade de energia transmitida por uma interface.

Para realizar o experimento, foi utilizado um laser com uma iluminância de $E_{V_{0}}=(11,9 \pm 0,1) k l u x$, medida na sua ponteira. Buscou-se variar o comprimento das varetas a partir da menor disponível. Destaca-se que, para varetas com comprimento maior do que $50 \mathrm{~cm}$, não foi detectada luz na extremidade oposta ao laser. Os dados experimentais coletados e o ajuste dos parâmetros iluminância inicial e o coeficiente de atenuação linear $\mu$ da Equação 13 estão representados na Figura 6.

Os parâmetros identificados por meio do ajuste foram:

$$
E_{V_{0}}=(7,7 \pm 0,5) k l u x \quad \text { e } \quad \mu=0,143 \pm 0,005 \mathrm{~cm}^{-1} .
$$

Para explicar a diferença entre o ajuste da iluminância inicial e o valor medido no laser, devemos considerar as perdas de energia luminosa na entrada e na saída do material devido à reflexão da luz e ao problema da rugosidade nas extremidades das varetas, onde houve o corte. Mesmo que as superfícies fossem perfeitamente planas, haveria perdas por reflexão. A partir das equações de Fresne 13 podemos mostrar que a perda de energia luminosa pelo processo de reflexão é de cerca de $4,26 \%$ para incidência normal da luz de um laser de 670nm em uma interface ar-vidro (com

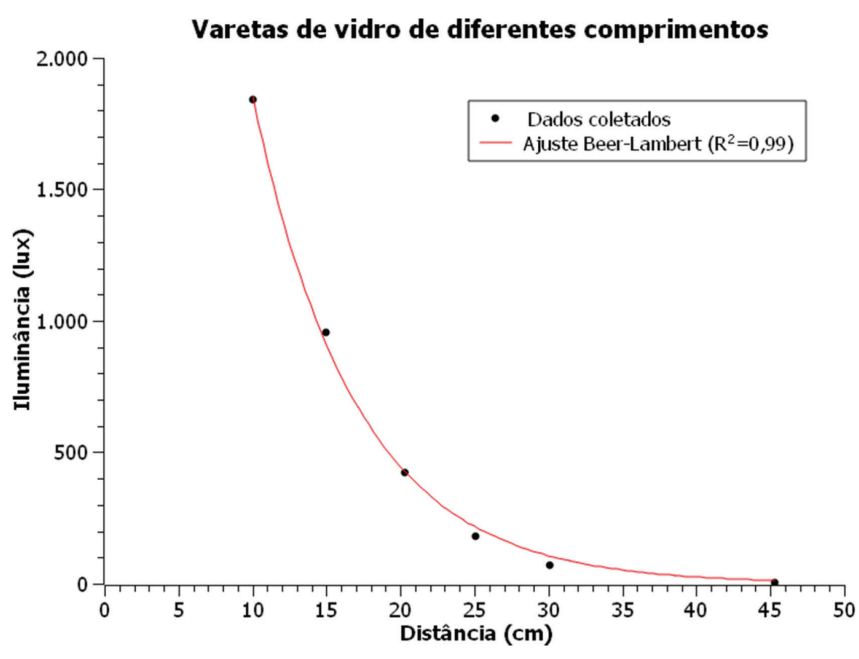

Figura 6: Ajuste do modelo teórico de propagação da luz em meios materiais aos dados experimentais da atenuação da luz no vidro.

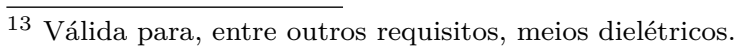




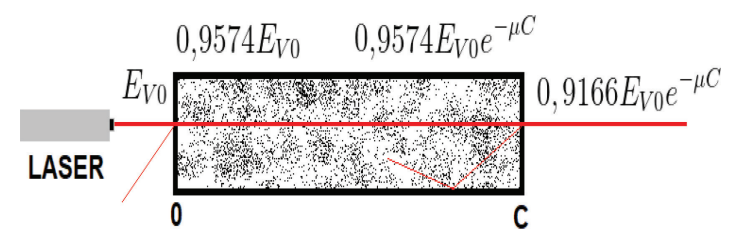

Figura 7: Perda de energia por reflexão da luz que incide normalmente sobre um material de comprimento $C$. A luz refletida forma ângulos apenas para fins de ilustração, já que, na incidência normal, a luz reflete sobre si mesma. Em cada interface, a iluminância do feixe diminui $4,26 \%$.

índice de refração $n=1,5204^{14}$, independente da luz estar entrando ou saindo do meio. Ou seja, como está indicado na Figura 7, quando a luz atravessa a interface ar-vidro, teoricamente sua iluminância cai imediatamente para $0,9574 E_{V_{0}}$ dentro do material. Pela Lei de Beer-Lambert, ao chegar na outra extremidade, se o caminho percorrido for $C$, a iluminância dentro do material é $0,9574 E_{V_{0}} e^{-\mu C}$. Ao passar pela interface vidro-ar final, diminui mais $4,26 \%$, resultando em uma medida de $0,9166 E_{V_{0}} e^{-\mu C}$ no luxímetro.

Levando em conta esses efeitos, a iluminância inicial ajustada deveria ser 10,9 klux, bem fora da incerteza associada ao valor obtido. Por isso, concluímos que a perda de energia luminosa provocada pela rugosidade do vidro é mais significativa do que a perda pela reflexão da luz.

O significado físico do coeficiente de atenuação pode ser interpretado em termos da distância de atenuação (livre caminho médio) $D$ da luz, que pela Equação 13 vale, aproximadamente, $7 \mathrm{~cm}$. Apesar desse valor ser relativamente pequeno, isso não implica que a radiação não alcance distâncias maiores (ou menores) no material. De fato, nessa distância, a iluminância se reduz a $37 \%$ do valor inicial, mas não se extingue. Foi só a partir de $50 \mathrm{~cm}$ que não foi mais possível detectar luz.

O coeficiente de atenuação linear obtido pode ser comparado com valores típicos para essa grandeza nos vidros transparentes. O mais comum é o chamado soda lime silica glass, usado, por exemplo, em janelas: para esse material, no comprimento de onda usado na investigação (670nm), $\mu=\mu_{A}+\mu_{E} \approx \mu_{A}$ [30, 31, onde $\mu_{A}=0,189 \mathrm{~cm}^{-1}$ [32]. Como o coeficiente de atenuação dos vidros depende tanto dos materiais usados no seu processo de fabricação [32], quanto dos elementos que lhe são acrescentados para diferentes fins (dopagem) [33], assume-se que a divergência entre o coeficiente de atenuação medido $\left(\mu=0,143 \pm 0,005 \mathrm{~cm}^{-1}\right)$ e o encontrado na literatura não invalida os resultados encontrados.

Finalmente, pela Figura 6, o ajuste do modelo aos dados foi satisfatório $\left(R^{2}=0,99\right)$, o que nos leva a concluir que o fenômeno da reflexão total não teve um efeito dominante. Para que a reflexão total ocorra e interfira

\footnotetext{
${ }^{14}$ Para vidro do tipo soda lime silica 32.
}

na medida, é necessário que a luz se espalhe ao longo do caminho, algo que não ocorre de forma intensa para os vidros, conforme apontado acima.

Por meio deste experimento, pode-se discutir três aspectos fundamentais da $\mathrm{MDC}^{+}$: i) o papel do controle de variáveis no delineamento e execução experimental, por exemplo, quando buscamos suavizar a interface dos materiais, minimizando perdas de energia; ii) a contrastação empírica como ferramenta para avaliar a adequação de um modelo para descrever um fenômeno; e iii) a necessidade (ou não) de expandi-lo frente aos propósitos do experimento: no presente estudo fica evidente que o modelo de propagação da luz no vácuo, que prevê iluminância independente da distância do laser, não é adequado, sendo necessário expandi-lo incluindo efeitos de absorção e espalhamento. Mesmo descrevendo a atenuação da luz no vidro de forma mais adequada, o modelo expandido não captura todos os efeitos e processos desse fenômeno, possuindo espaço para melhorias. Por exemplo, a influência da reflexão total da luz poderia ser incorporado em um modelo que busca descrever a atenuação de uma componente da radiação cujo espalhamento não seja desprezível no vidro. No contexto de sala de aula, esse tipo de constatação pode suscitar debates sobre o caráter provisório das construções científicas, um aspecto fundamental sobre a natureza da ciência, afastando a concepção comum entre os estudantes de que o conhecimento científico é imutável.

\subsection{Atenuação da luz nos líquidos}

A seguinte investigação é proposta pelo professor:

A zona fótica dos oceanos é de importância ecológica fundamental: nessa região encontra-se a maior parte da vida marinha e nela ocorre a fotossintese pelas algas, responsáveis por mais de $50 \%$ da produção de oxigênio global. Avalie a atenuação da energia luminosa da luz no meio marinho.

As condições aquáticas do meio oceânico podem ser replicadas tanto pela coleta de uma amostra de água do mar quanto pela produção artificial da sua composição por meio de uma solução aquosa contendo uma mistura de diferentes sais. Uma alternativa prática, adotada nesta investigação, é considerar a salinidade média do oceano (35 g/L) como referência e produzir uma solução com água de torneira e sal de cozinha, já que, no Brasil, 98\% deste produto é $\mathrm{NaCl}$ [34].

Para avaliar a atenuação da luz em função da distância percorrida no meio, diferentes profundidades (ou caminhos óticos) podem ser simuladas por meio de uma coluna de líquido em um cano, por exemplo. Em vez de investigar a atenuação da luz solar como um todo, podemos concentrar o estudo da atenuação de uma componente da luz solar apenas, pois, assim como o olho humano, as células responsáveis pela fotossíntese são mais sensíveis a determinados comprimentos de onda do que outros. Utilizando um laser, por exemplo, 


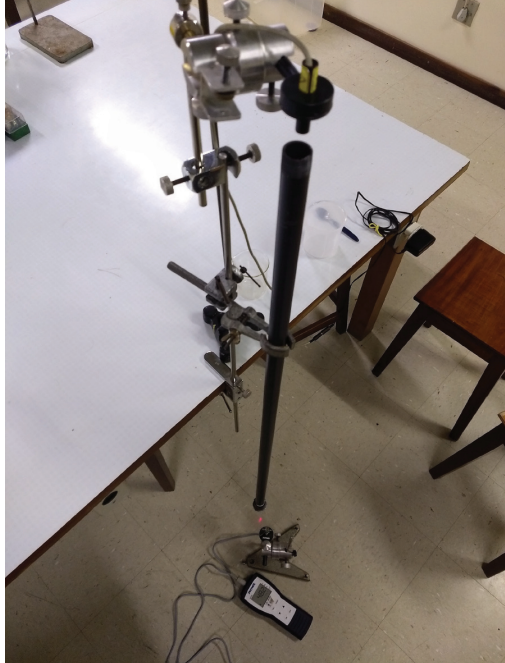

Figura 8: Montagem experimental usada para avaliar a atenuação da luz em líquidos.

podemos estudar a atenuação de um comprimento de onda específico do espectro eletromagnético do Sol.

Uma montagem experimental que permite realizar a investigação proposta está ilustrada na Figura 8. Essa estrutura se constitui em uma haste fixada verticalmente na mesa, sustentando um cano de PVC, também na vertical, e um laser alinhado de forma que o seu feixe de luz passa pelo interior do cano, atingindo o luxímetro posicionado no chão. O cano é aberto na extremidade superior e vedado na inferior por meio de uma chapa de vidro colada em uma luva de PVC rosqueada no cano. O vidro é posicionado na horizontal e precisa ser bem vedado, pois será colocada água salgada gradativamente dentro do cano para investigar o comportamento da atenuação da luz em função da profundidade da coluna de líquido em seu interior. É importante que o sal seja totalmente dissolvido antes da água ser adicionada no cano para evitar decantação no fundo, impedindo a passagem de luz. Além disso, o vidro deve ser suficientemente grosso para suportar a pressão da coluna d'água acima dele.

Este sistema usa uma fonte de luz colimada e se comporta - do ponto de vista da satisfação das idealizações assumidas pelo modelo teórico de propagação da luz em meios materiais - de forma semelhante ao vidro, já discutida na seção anterior. A principal diferença é que a luz espalhada não pode abandonar o cano, estando totalmente confinada. Foi utilizado um cano preto pois espera-se que a radiação espalhada pela água fosse absorvida pelas paredes do material, evitando sua detecção pelo luxímetro. Esse procedimento de controle de variáveis é importante porque a água salgada espalha a luz mais do que a água pura, mesmo dissolvendo o sal completamente.

Para determinar a altura $h$ da coluna de líquido dentro do cano, vamos idealizá-lo como sendo perfeitamente cilíndrico e que não existe tensão superficial capaz de criar o chamado menisco curvo, alterando a altura efetiva da coluna de líquido. Nesse caso, a altura $h$ pode ser determinada usando o diâmetro $d$ interno do cano e o volume $V$ de líquido colocado no seu interior, pela relação $h=4 V / \pi d^{2}$. Conforme apontado na $\mathrm{MDC}^{+}$, investigações empíricas podem ser amparadas por modelos teóricos auxiliares. Neste caso, o modelo teórico auxiliar tem a função de fundamentar a inferência de uma grandeza $(h)$ a partir de outras duas $(V, d)$, sendo que, para o uso do próprio modelo, são supostas idealizações, o que frequentemente não é levado em consideração no processo de contrastação empírica.

Destaca-se como fontes de erro que comprometem as idealizações assumidas no modelo de Beer-Lambert: i) as perdas por reflexão na interface ar-água, águavidro e vidro-ar; ii) a concavidade na superfície da água provocada pelo menisco curvo, que provoca aumento na cintura do feixe de laser, que passa a divergir levemente - do ponto de vista do luxímetro, portanto, é como se estivesse entrando uma menor quantidade de luz na água; iii) a perda das propriedades dielétricas do meio por conta da adição de sal - a presença de cargas favorece uma interação inelástica entre a radiação e o meio, já que parte da energia da luz é dissipada mecanicamente quando os íons oscilam pela interação com os campos eletromagnéticos da onda [35. Esse efeito não é abarcado pela Lei de Beer-Lambert, de forma que a idealização assumida de que a interação da luz com a matéria se dá unicamente por absorção ou espalhamento não é respeitada.

Antes de realizar a coleta de dados, fixamos um laser $\left(\lambda_{L}=670 \mathrm{~nm}\right)$ na haste firmement ${ }^{15}$ alinhando o feixe luminoso de forma a incidir diretamente sobre o detector. Sem água, com a luz do laser passando através da chapa de vidro, foi detectada uma iluminância de $E_{V_{0}}=(74,4 \pm 0,1) k l u x$. Adicionando água com sal gradativamente no cano, foram coletados os dados sintetizados na Figura 9

Na Figura 9, também está representado o ajuste dos parâmetros $E_{V_{0}}$ e $\mu$, obtidos com a Lei de Beer-Lambert (Equação 13), aos dados experimentais. Os valores encontrados para essas grandezas foram os seguintes:

$$
E_{V_{0}}=(29 \pm 1) k l u x \quad \text { e } \quad \mu=0,029 \pm 0,002 \mathrm{~cm}^{-1} .
$$

Apesar da adequação do ajuste $\left(R^{2}=0,98\right)$ aos dados coletados, há grande diferença entre a iluminância do laser $((74,4 \pm 0,1)$ klux $)$ e o parâmetro $E_{V_{0}}$ ajustado uma redução de $60 \%$. Conforme mencionamos anteriormente, era esperado certa divergência da luz do laser a partir da superfície da água pela lente formada pelo menisco curvo. Por isso acreditamos que essa fonte de erro tenha sido a responsável pela diferença observada na iluminância inicial.

A partir do coeficiente de atenuação ajustado, se obtém uma distância de atenuação $D$ (livre caminho

\footnotetext{
15 À medida que colocamos água no cano, o peso da estrutura aumenta, tendendo a perder seu alinhamento se não estiver muito bem fixada.
} 


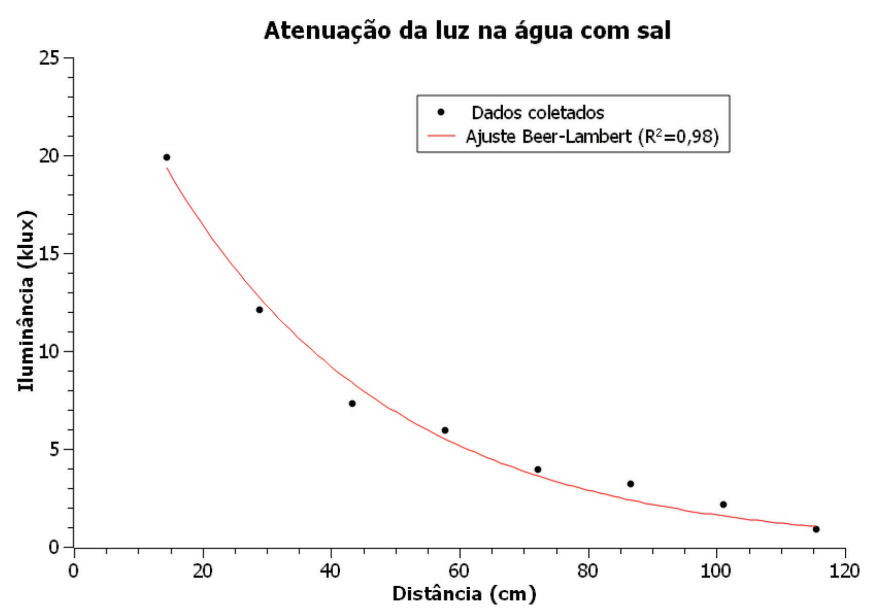

Figura 9: Ajuste do modelo teórico de propagação da luz em meios materiais aos dados experimentais da atenuação da luz na água com sal.

médio) de $35 \mathrm{~cm}$. Esse valor é cinco vezes maior que aquele obtido para o vidro.

O coeficiente de atenuação obtido pode ser comparado com seu valor típico para a água do mar $\mu \approx$ $\mu_{A}=0,01 \mathrm{~cm}^{-1}$ para o comprimento de onda usado no experimento $(670 \mathrm{~nm})$ [36]. Os principais fatores que contribuem para a diferença observada devem ser a composição da solução de água com sal utilizada e os problemas associados ao menisco curvo:

- na água oceânica, como já mencionado, cerca de $80 \%$ do sal presente é $\mathrm{NaCl}$, enquanto no experimento esse percentual foi praticamente 100\%; além disso, a água de torneira contém minerais e impurezas 37 não presentes no oceano. Há ainda diferença na concentração de íons de sódio (Na) e cloro $(\mathrm{Cl})$ de, aproximadamente, $40 \%$ e $60 \%$ em massa, respectivamente [23], enquanto no sal de cozinha a concentração de sódio é maior do que a de cloro 38 .

- à medida que a altura da coluna d'água dentro do cano se eleva, a 'lente' do menisco espalha a luz por uma área maior na saída do cano, diminuindo a iluminância. Esse fator ficou evidente durante as medições, quando se observou que o feixe de luz do laser aumentava gradualmente de diâmetro à medida que a coluna d'água aumentava. Ambos os fatores podem ter contribuído para aumentar a atenuação da luz, diminuindo seu livre caminho médio.

Mais do que reproduzir procedimentos e resultados expostos na literatura, um EM tem enfoque em discussões didáticas sobre conceitos científicos, dando especial destaque para aqueles relacionados com o processo de modelagem científica (e.g. idealização, grau de precisão, controle de variável, contrastação empírica, expansão do modelo). Dessa perspectiva, a divergência encontrada entre o coeficiente de atenuação medido e o dos oceanos representa uma oportunidade para se promover discussões sobre um aspecto chave do laboratório: a influência de fatores não considerados nos modelos teóricos usados nas investigações experimentais. Essa situação tem potencial para dar sentido ao conceito de controle de variáveis, por meio de debates sobre o caráter artificial dos objetos e eventos explorados em laboratórios de Física, já que eles são produzidos a partir de representações simplificadas da realidade (neste caso, a partir de uma representação da atenuação da luz nos oceanos).

A partir dessas discussões, percebe-se como a modelagem permeia o delineamento, execução e análise do experimento: a investigação do evento real (atenuação da luz solar na água do mar) foi simplificada pela utilização de apenas um comprimento de onda da luz e um cano vedado com uma altura de líquido variável. Desta forma, foi criada uma situação artificial, controlada, mais simples, buscando compreender um fenômeno mais complexo. A seguir, foi delineado um aparato experimental com enfoque no controle de variáveis, buscando satisfazer as idealizações do modelo teórico de referência. Isso ocorreu quando usamos um cano preto, com o objetivo de absorver a luz espalhada. Para obter a altura da coluna d'água foi utilizado um modelo teórico auxiliar que tem suas próprias idealizações (cano perfeitamente cilíndrico, inexistência do menisco curvo). Na análise, buscou-se justificar as diferenças entre predições e evidências tanto através da avaliação do grau de adequação do controle de variáveis realizado no experimento (a perda do paralelismo do feixe de luz depois de entrar na água e a perda de energia em cada interface, composição química da água) quanto pela constatação de que algumas idealizações assumidas pelo modelo não foram respeitadas (interação inelástica da radiação com a matéria).

\subsection{Atenuação da luz na fumaça}

A investigação proposta pelo professor é:

Os detectores de fumaça fotoelétricos são dispositivos essenciais na contenção de incêndios. O princípio de funcionamento deste equipamento é baseado na atenuação da luz provocada pela fumaça, que deixa de ser detectada por um sensor, disparando o alarme. Avalie a atenuação da energia luminosa pela fumaça.

A "fumaça" — denominação genérica do produto gasoso da combustão de certos materiais, como gasolina, madeira, plástico, etc. — pode ser produzida no laboratório didático por um pequeno festim feito com algumas cabeças de fósforo enroladas em papel-alumínio, conforme ilustrado pela Figura 10.

Para medir a atenuação da luz, foi utilizada a montagem apresentada na Figura 11.

Optou-se por utilizar uma lâmpada incandescente de bulbo com objetivo de observar a atenuação da luz por uma fonte pontual, já que os outros dois experimentos 


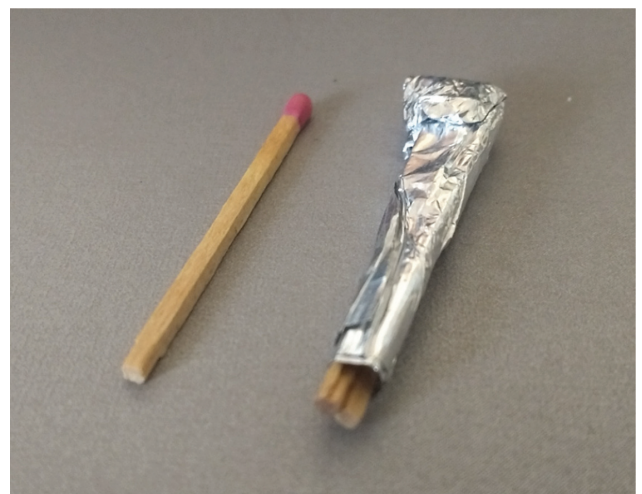

Figura 10: Festim utilizado para introduzir a fumaça dentro do cano. A extremidade fechada contém 6 cabeças de fósforo.

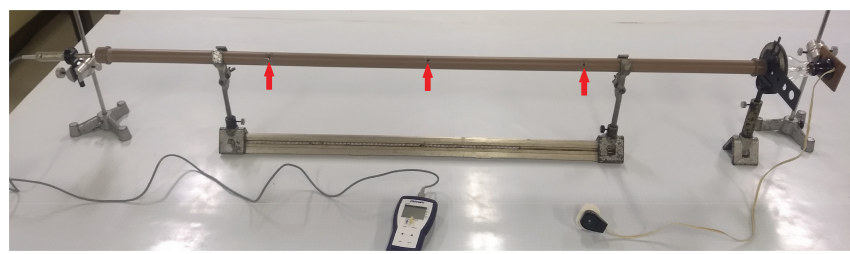

Figura 11: Aparato experimental utilizado para investigar a atenuação da luz pela fumaça. À esquerda do cano, um luxímetro; à direita, uma lâmpada incandescente. As extremidades do cano estão parcialmente vedadas por um tampão com um furo no centro, permitindo entrada e saída de luz. Existe uma placa metálica com furos circulares de tamanhos diferentes entre a lâmpada e o tampão. Foram feitos 3 furos (indicados pelas setas) ao longo do cano, por onde se insere a fumaça responsável por atenuar a luz no caminho ótico do cano.

foram feitos com fonte colimada. O festim é posicionado em um dos furos feitos ao longo do cano e aceso para produzir a fumaça. Após a ignição, o festim é retirado e o orifício vedado com fita para evitar a saída da fumaça. Mesmo assim, como as extremidades do cano são abertas por conta do orifício central na tampa, a fumaça sai gradualmente do cano, ficando menos densa. O coeficiente de atenuação da fumaça pode ser determinado medindo a iluminância $E_{V}$ da lâmpada na extremidade do cano através da Equação (18), dado que seu comprimento e o fluxo luminoso $\Phi_{V_{0}}$ da lâmpada sejam conhecidos. A Figura 12 ilustra a quantidade de luz que chega no luxímetro quanto não há fumaça.

O experimento tem objetivo de analisar a atenuação de luz de uma fonte pontual e isotrópica. Porém, essa hipótese é comprometida uma vez que o filamento da lâmpada tem cerca de $3 \mathrm{~cm}$ e um formato cilíndrico. Por isso, foi introduzida uma placa metálica entre a lâmpada e a entrada do cano que permitia a passagem da luz por um orifício circular com $1 \mathrm{~mm}$ de diâmetro. Desta forma, considera-se que a fonte pontual não é a lâmpada em si, mas o orifício da placa metálica.

Uma vantagem dessa montagem é que a luz não precisa atravessar qualquer interface desde que sai do

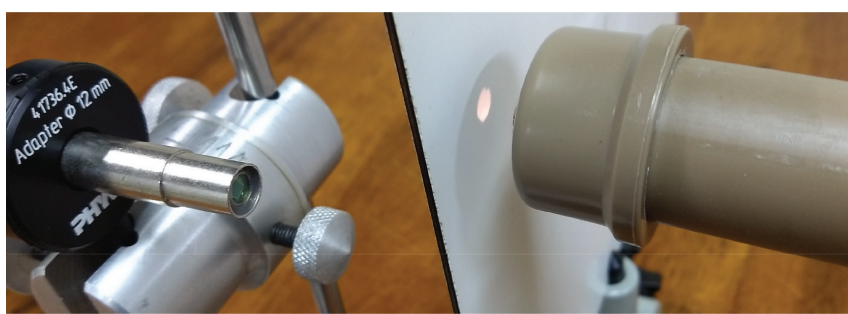

Figura 12: Projeção da luz que atinge o luxímetro devido à fonte pontual quando não há fumaça dentro do cano. Durante as medidas, o luxímetro é posicionado rente à saída do cano, dificultando a saída da fumaça. O mesmo acontece do outro lado do cano, onde a placa metálica bloqueia a saída parcialmente.

orifício até o luxímetro, já que há um orifício nos tampões nas extremidades do cano. Desta forma, uma importante fonte de erro nos experimentos anteriores não existe nesta situação. Além disso, o cano contribui para absorver a luz espalhada pela fumaça, sendo esse um importante controle de variável do experimento.

Antes de colocar a fumaça no cano, alinhou-se o detector, cano, placa furada e lâmpada acesa de forma que a luz incidisse diretamente no detector. O orifício central do cano tem mais ou menos o mesmo tamanho do detector, como pode ser visto pela projeção da luz na Figura 12, Para determinar o fluxo luminoso $\Phi_{V_{0}}$ que atravessa o furo da placa metálica, levou-se em consideração que o livre caminho médio da luz visível no ar é desprezível. De fato, a distância de atenuação da luz na atmosfera é da ordem de dezenas de quilômetros [39]. Logo, pode-se utilizar a Equação (5) para calcular o fluxo luminoso.

A distância entre as duas extremidades do cano é de $1,550 \pm 0,005 \mathrm{~m}$ e a iluminância medida na sua saída, sem fumaça no seu interior, 106,0 $\pm 0,1$ lux. Pela Equação (5), o fluxo luminoso emitido pela fonte pontual é $\Phi_{V_{0}}=(320 \pm 2) .10 \mathrm{~lm}$. Esse valor, bem como sua incerteza associada, são utilizados para a determinação do coeficiente de atenuação da fumaça.

Em seguida, sem alterar a disposição dos equipamentos, foi inserido um único festim no orifício central do cano e a fumaça foi gerada através de sua ignição. O festim foi retirado e o orifício coberto com fita. Só foram coletados dados de iluminância depois de alguns segundos, quando as extremidades do cano começaram a fumegar. Isso garantiu que o caminho ótico da luz, desde a placa até o luxímetro, fosse completamente através da fumaça. Com os dados de iluminância, foi possível usar a Equação (18) para determinar o coeficiente de atenuação da fumaça em função do tempo, como indicado na Figura 13

Os valores de $\mu$ diminuem ao longo do tempo à medida que a fumaça se dissipa dentro do cano. Considerando o menor e o maior coeficiente de atenuação calculado, verifica-se que o livre caminho médio da luz na fumaça está entre $1,25 \mathrm{~m}$ e $5 \mathrm{~m}$, faixa de valores condizentes com 


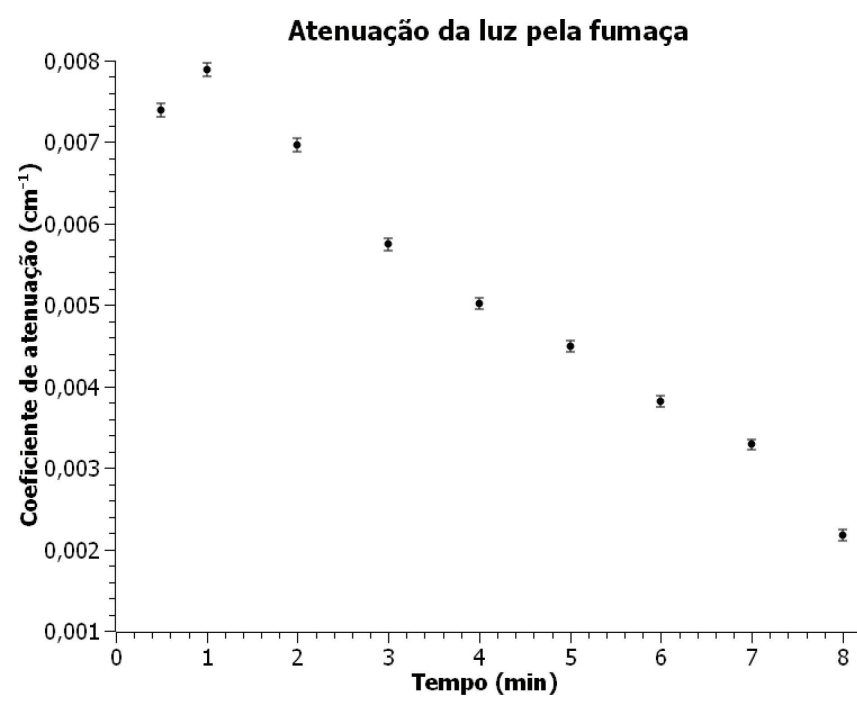

Figura 13: Coeficiente de atenuação da fumaça calculado a partir do modelo teórico de propagação da luz em meios materiais quando a fonte emissora é pontual.

a literatura para fumaça proveniente da combustão de diferentes materiais [40, 41.

Como principais fontes de erro na determinação do coeficiente de atenuação no experimento, podemos destacar a reflexão da luz no interior do cano (mesmo sendo escuro) e a deposição da fumaça na superfície do luxímetro, podendo torná-la opaca e consequentemente absorvendo mais luz, o que pode ocorrer quando há muita fumaça dentro do cano. No entanto, esse efeito não foi importante no experimento, pois não se verificou significativa deposição de partículas no sensor.

É interessante lembrar que neste experimento foi utilizada luz branca, não monocromática. Por isso, o coeficiente de atenuação determinado resulta de uma seção de choque efetiva $(\sigma=\sigma(\lambda))$, ponderada pelo espectro de emissão da lâmpada incandescente. Assim, o livre caminho médio obtido representa uma espécie de média das distâncias de atenuação de cada um dos comprimentos de onda da luz branca na fumaça.

Como pode ser constatado na Figura 13, a densidade da fumaça influencia fortemente a atenuação da luz. Então, para comparar a diferença entre as predições dos dois modelos de propagação da luz (no vácuo e em meio material) tomamos o coeficiente de atenuação $\mu=0,005 \mathrm{~cm}^{-1}$ e $\Phi_{V}=\Phi_{V_{0}}=3.200 \mathrm{~lm}$ e usamos as Eqs. 5 e 19 para gerar a Figura 14.

A figura mostra a diferença percentual entre as predições dos dois modelos teóricos. Nessa situação, podemos identificar que a Lei de Beer-Lambert difere da lei de propagação da luz no vácuo em torno de $40 \%$ para distâncias de $1 \mathrm{~m}$. Esse tipo de constatação pode servir para ilustrar o domínio de validade do modelo de propagação da luz no vácuo na situação em que se tem fumaça no ambiente, dependendo da margem de erro com que se aceita trabalhar.

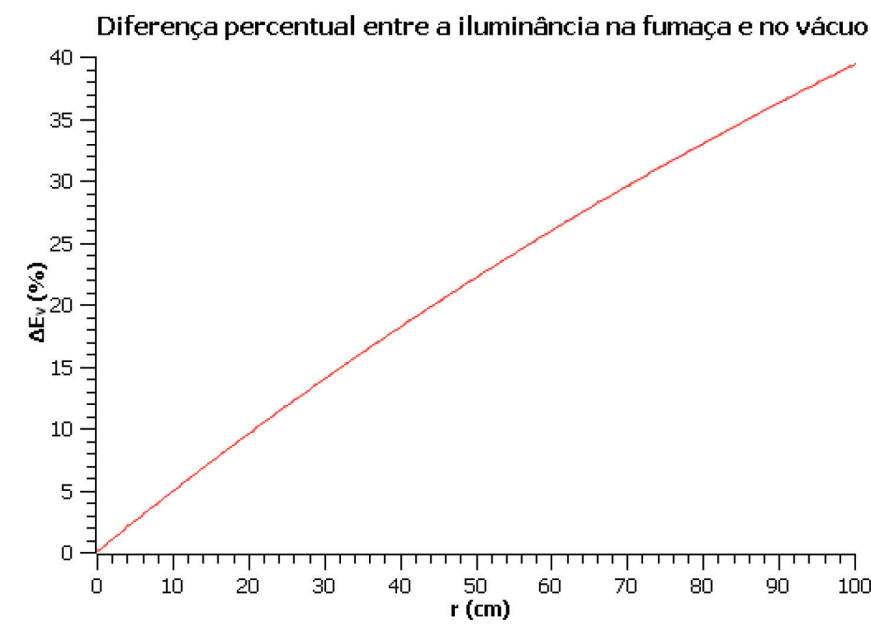

Figura 14: Comparação entre predições obtidas com o modelo teórico de propagação da luz no vácuo e o modelo de propagação em meios materiais para uma fonte com fluxo luminoso de $\Phi_{V}=$ $3.200 \mathrm{~lm}$ e um coeficiente de atenuação da luz pela fumaça de $\mu=0,005 \mathrm{~cm}^{-1}$.

Além disso, o conhecimento construído com a investigação pode suscitar debates sobre políticas públicas que versam, por exemplo, sobre a obrigatoriedade de se instalar determinada quantidade de luzes de emergência com sensores de fumaça em ambientes fechados, com o objetivo de iluminar uma possível rota de fuga em uma situação de incêndio.

Conforme foi ilustrado através do processo de contrastação empírica nesse experimento, ao utilizar um modelo mais sofisticado, obtém-se melhorias do ponto de vista da descrição do fenômeno físico, porém, o foco da atividade é levar o aluno a pensar sobre os fatores incluídos na construção do modelo que levaram a esse maior grau de precisão. Nesse sentido, o experimento contribui para o processo de formação do aluno na medida em que fomenta o pensamento crítico e reflexões sobre o processo de construção do conhecimento científico. Ademais, nem sempre o ganho alcançado justifica deixar de usar um modelo mais simples, mas que descreve o fenômeno dentro do grau de precisão desejado. Conforme aponta a $\mathrm{MDC}^{+}$, o ensino de ciências na escola e na academia se dá por meio de modelos didáticos-científicos, que costumam ser modelos mais simples, porém que descrevem uma ampla gama de fenômenos. Se não acompanhados por discussões sobre a natureza da ciência e do fazer científico, os alunos frequentemente partem da premissa de que os modelos são descrições fiéis da realidade, não estando cientes sobre as idealizações assumidas na sua construção, nem seu domínio de validade. Nesse sentido, acreditamos que a atividade apresentada se destaca, pois, ao comparar dois modelos científicos que descrevem o mesmo fenômeno, abre espaço para discussões sobre o caráter representacional desses modelos, chamando atenção para suas limitações e potencialidades na descrição do fenômeno. 


\section{Respostas às questões enunciadas}

Neste artigo propusemos uma situação-problema, potencialmente instigante, relacionada à preservação de microrganismos na chamada zona fótica dos oceanos. Como é característico de um EM, para a construção de conhecimentos necessários para solucionar a situaçãoproblema proposta, partimos para questões específicas, passíveis de serem investigadas em situações artificiais, manipuláveis no laboratório didático.

É preciso reiterar que, em contraposição a abordagens mais fechadas, cujo foco se concentra na obtenção de um resultado já bem conhecido, nos EM o foco está na modelagem de sistemas/fenômenos físicos e na autonomia do estudante. Sendo assim, os estudantes decidem não somente que questão específica responderão, mas também, por exemplo, o modelo teórico que embasará as investigações, o controle de variáveis que minimizará fatores não levados em conta nesse modelo, a montagem experimental, o procedimento de coleta e análise de dados, e a apresentação final desses procedimentos, resultados e conclusões. Esperam-se respostas mais conceituais, que não se limitem a contrastação empírica de valores.

Como ilustração, neste artigo descrevemos três experimentos sobre a atenuação da luz, que podem ser conduzidos em um laboratório didático típico de ótica em nível de Física Geral. Apresentamos, na sequência, as respostas construídas para as duas questões específicas enunciadas.

Duas questões específicas foram enunciadas e vamos respondê-las.

"Como se dá a atenuação da energia luminosa ao atravessar meios materiais?" pode ser respondida com base nos resultados obtidos dos experimentos: A atenuação da energia luminosa pelos meios depende tanto do tipo de fonte luminosa, quanto do meio material em questão. Corroborando as predições do modelo teórico de atenuação da luz em meios materiais (Quadro 1), foi identificado um decaimento exponencial da iluminância com a distância percorrida no meio nos experimentos realizados com fontes aproximadamente colimadas (lasers). Já no caso envolvendo uma fonte aproximadamente pontual e isotrópica (lâmpada), a atenuação é mais intensa, possuindo uma componente de decaimento inversamente proporcional a $r^{2}$, além da componente exponencial, o que também corrobora as predições do modelo de Beer-Lambert. Em particular, foram obtidos coeficientes de atenuação da luz para a fumaça $\left(\mu_{F}\right)$, água com sal $\left(\mu_{A S}\right)$ e vidro $\left(\mu_{V}\right)$, sendo que $\mu_{F}<\mu_{A S}<\mu_{V}$.

"Como a poluição dos oceanos pode influenciar a fotossintese das algas por meio de alterações na atenuação da luz solar?" pode ser parcialmente respondida com base no entendimento construído com os experimentos juntamente com informações sobre o processo de fotossíntese no mar: a profundidade máxima da zona fótica oceânica, onde a fotossíntese pelas algas ainda ocorre, é em torno de $120 \mathrm{~m}$, dependendo das condições locais [42]. No entanto, nem todas as componentes da radiação solar atingem essa profundidade. De fato, no ambiente marinho, luz com comprimento de onda mais longo sofre mais atenuação que luz de comprimento de onda mais curto. Essa informação é relevante para responder à questão porque a produção de oxigênio pelas algas fotossintéticas é uma função tanto seu comprimento de onda (dependendo da espécie de alga) 43, quanto da intensidade da radiação incidente [44], isto é, de sua iluminância.

A poluição nos oceanos pode afetar a dinâmica do processo fotossintético essencialmente por dois mecanismos: alteração no ciclo bioquímico nas algas e absorção da luz. Como mencionado, não é pretensão do artigo discutir processos bioquímicos. Já sobre a absorção, podemos argumentar primeiramente que, independente do caminho ótico percorrido pela luz na água, certo poluente pode ser nocivo para as algas simplesmente por absorver comprimentos de onda específicos do espectro solar que são mais eficientes para o processo fotossintético. Desta forma, mesmo que haja luz no ambiente aquático, a produção de oxigênio fica comprometida. Outros agentes poluentes podem prejudicar a fotossíntese pelo bloqueio da luz, que pode ocorrer por exemplo, por meio de uma camada de óleo na superfície, ou de forma homogênea ao longo do meio, provocando turbidez. A investigação realizada, mesmo que com água e sal de cozinha, permite fazer inferências sobre a atenuação de uma componente do espectro eletromagnético solar $(670 \mathrm{~nm})$ ao longo de um percurso ótico definido.

Com o valor encontrado no experimento, a intensidade da luz diminui para $1 \%$ de seu valor na superfície a uma profundidade de 1,6 m. A adição de poluentes na água tem potencial de diminuir a taxa de fotossíntese das algas aumentando o coeficiente de atenuação da luz na água pelos processos de absorção e espalhamento. Por exemplo, tomando como referência o experimento realizado, se o poluente aumentasse em $10 \%$ o coeficiente de atenuação da água, a luz se extinguiria para $1 \%$ de seu valor na superfície a uma distância de 1,45 m, uma redução de cerca de $9 \%$ na penetração da luz.

Com isso, a atividade responde às duas questões levantadas inicialmente, construindo conhecimento relevante sobre o fenômeno estudado e deixando espaço para novas investigações sobre o tópico em questão. Por exemplo, poder-se-ia fazer a mesma investigação porém com laser de outro comprimento de onda, ou com água poluída.

\section{Comentários finais}

Duas observações são pertinentes sobre as implementações deste EM conduzidas no Instituto de Física da UFRGS no segundo semestre de 2019.

Observamos que cinco grupos, dos oito, cada um com quatro estudantes, não utilizaram a liberdade que lhes 
foi concedida para criar suas próprias investigações, preferindo construir experimentos baseados nas propostas do guia. Conceber experimentos não é tarefa fácil, no entanto, os grupos que decidiram inovar foram criativos optando por investigar situações de interesse atual. Por exemplo, um grupo decidiu investigar a atenuação da luz na água com pedaços triturados de plástico transparente, simulando os microplásticos no oceano; já outro, usou água com cinzas para avaliar o impacto da poluição de São Paulo decorrente das queimadas amazônicas. É preciso reiterar que, mesmo quando optaram pelas propostas investigativas do guia, os estudantes tiveram que tomar decisões sobre o delineamento da investigação e construção dos aparatos experimentais explorados, desenvolvendo, em algum nível, suas autonomias.

Destacamos que a introdução de EM em uma disciplina de laboratório da grade curricular implica abrir mão de alguns experimentos tradicionalmente realizados nessa disciplina. Por exemplo, dos 12 experimentos regulares da disciplina de Física Experimental IV em que o presente episódio foi aplicado, sete foram substituídos por quatro EM - um deles é o apresentado neste artigo. Dos cinco experimentos restantes, exigiu-se apenas dois relatórios como forma de mitigar a carga de trabalho da disciplina. Reconhecemos que ainda assim a carga de trabalho requerida foi excessiva para uma disciplina de dois créditos (duas horas-aula semanais).

Como perspectiva futura apontamos o término de um estudo que investiga contribuições desse e de outros EM para que os estudantes ampliem seus domínios sobre o campo conceitual da modelagem didático-científica, cujos resultados serão divulgados em breve.

\section{Agradecimento}

Agradecemos à professora Cilâine Verônica Teixeira pelas importantes contribuições no delineamento das atividades descritas neste artigo. Agradecemos também ao árbitro da RBEF e ao professor Ricardo Rego Bordalo Correia pelas críticas dirigidas ao artigo que em muito contribuíram para a sua melhoria.

\section{Referências}

[1] A. Gaspar, Educação: revista de estudos da educação 13, 71 (2004).

[2] D. Hodson, Enseñanza de las Ciencias 12, 299 (1994).

[3] A. Borges, Caderno Brasileiro de Ensino de Física 24, 9 (2002).

[4] R. Trumper, Science \& Education 12, 645 (2003).

[5] M. Pietrocola, Investigações em Ensino de Ciências 4, 213 (1999).

[6] C.J. Boulter e J. K. Gilbert, Challanges and opportunities of developing models in science education (Kluwer Academic Publishers, Netherlands, 2000).

[7] D. Hestenes, GIREP Conference (Alphabase, Netherlands, 2006).
[8] I.T. Koponen, Science \& Education 16, 751 (2007).

[9] R.V. Brandão, I.S. Araujo e E.A. Veit, Caderno Brasileiro de Ensino de Física 28, 507 (2011).

[10] L.A. Heidemann, I.S. Araujo e E.A. Veit, Caderno Brasileiro de Ensino de Física 29, 965 (2012).

[11] A.A. Adúriz-Bravo, Science \& Education 22, 1593 (2013).

[12] L.A. Heidemann, I.S. Araujo e E.A. Veit, Investigações em Ensino de Ciências 23, 352 (2018).

[13] M. Pietrocola, Investigações em Ensino de Ciências 4, 213 (1999).

[14] J. Jackson, L. Dukerich e D. Hestenes, Science Educator 17, 10 (2008).

[15] J. Gilbert, International Journal of Science and Mathematics Education 2, 115 (2004).

[16] I.T. Koponen, Science \& Education 16, 751 (2007).

[17] L.A. Heidemann, Ressignificação das atividades experimentais no ensino de física por meio do enfoque no processo de modelagem científica. Tese de Doutorado, Universidade Federal do Rio Grande do Sul, Porto Alegre (2015).

[18] L.A. Heidemann, I.S. Araujo e E.A. Veit, Revista Brasileira de Ensino de Física 38, 1504 (2016).

[19] A. Moacir, P. Marcelo, C. Sara, P. Ernani, R. Satish, T. Richard e C. Pio, Ecotoxicology and Environmental Safety 71, 1 (2008).

[20] Carl J. Sindermann, Ocean Pollution: Effects on Living Resources and Human (CRC Press, New York, 1996).

[21] X. Han, Y.Peng, Y. Zhang, Z. Ma e J. Wang, Journal of the European Optical Society 10, 15045 (2015).

[22] F. Millero, R. Feistel, D. Wright e J. McDougall, DeepSea Research 55, 50 (2008).

[23] B. Wozniak e J. Dera, Light Absorption in Sea Water (Springer, New York, 2006).

[24] R. Weber, C. Teixeira, L. Heidemann e E. Veit, Episódio de Modelagem "Atenuação da Luz", disponível em: https://lief.if.ufrgs.br/pub/cref/rd/n07_Weber/index2. html, acessado em 13/08/2020.

[25] A.B. Kostinski, Optical Society of America 18, 1929 (2001).

[26] C.F. Bohren e D.R. Huffman, Absorption and Scattering of Light by Small Particles (Wiley, New York, 1983).

[27] CIE, The Basis of Physical Photometry — Technical Report, Commission Internationale de l'Éclairage, Vienna (2019).

[28] W. Arnott, K. Hamasha, H. Moosmüller, J. Sheridan e A. Ogren, Aerosol Science and Technology 39, 17 (2005).

[29] D. Halliday, R. Resnick e J. Walker, Fundamentos de Física: Óptica e Física Moderna (Rio de Janeiro, Editora LTC, 8 ${ }^{\text {a }}$ Ed., 2009), v. 4, p. 33.

[30] N.S. Andreev, Journal of Non-Crystalline Solids 30, 99 (1978).

[31] A. Jacobsen, N. Neuroth e F. Reitmayer, The american ceramic society 54, 186 (1971).

[32] M. Rubin, Solar Energy Materials 12, 275 (1985).

[33] S. Berneschi, M. Bettinelli, M. Brenci, R. Dall'Igna, G. Nunzi, S. Pelli, B. Profilo, S. Sebastiani, A. Speghini e G. Righini, Optical Materials 28, 1271 (2006).

[34] A. Pereira, A. Belinski, N. Valus e F. Beltrame, Iniciação Científica CESUMAR 10, 97 (2008). 
[35] J.D. Jackson, Classical Electrodynamics (John Wiley \& Sons, New York, 1962).

[36] G. Riccobene, A. Capone, S. Aiello, M. Ambriola, F. Ameli, I. Amore, M. Anghinolfi, A. Anzalone, C. Avanzini, G. Barbarino et al., Astroparticle Physics 27, 1 (2007).

[37] E. Richter, A. Fornaro, C. Lago e L. Angnes, Química Nova 30, 1147 (2007).

[38] A. Bastos, H. Carvalho, A. Silva e L. Araujo, Journal of Engineering and Exact Sciences 3, 678 (2017).

[39] V.E. Zuev, Laser-light transmission through the atmosphere (Springer, Berlin, 1976).

[40] T. Rinne, J. Hietaniemi e S. Hostikka, VTT Working Papers 66, 4 (2007).

[41] F.W. John, Combustion Science and Technology 175, 2299 (2003).

[42] C. Lorenzen, ICES Journal of Marine Science 34, 262 (1972).

[43] F.T. Haxo e L.R. Blinks, The Journal of General Physiology 33, 389 (1950).

[44] P. Eilersm e J. Peeters, Ecological Modelling 42, 199 (1988). 